PontIFícIa UniVERSIDADE CATÓLICA dO RIO DE JANEIRO

\title{
Treinamento Corporativo: repercussão na Empresa X
}

\author{
Matheus Garcia de Andrade Lima
}

Trabalho de Conclusão de Curso

Centro de CIÊnCIAS SOCIAIS - CCS DEPARTAMENTO de AdMINISTRAÇÃo

Graduação em Administração de Empresas 


\section{Matheus Garcia de Andrade Lima}

\section{Treinamento Corporativo: Repercussão na Empresa X}

\section{Trabalho de Conclusão de Curso}

Trabalho de Conclusão de Curso, apresentado ao programa de graduação em Administração da PUC-Rio como requisito parcial para a obtenção do titulo de graduação em Administração.

Orientadora: Andréa Bittencourt 
"O treinamento é uma ferramenta indispensável para que a organização

aprenda".

(GONÇALVES, 2017). 
Agradeço à minha orientadora, a professora Andréa Bittencourt, pela orientação e conhecimentos transmitidos durante a realização deste trabalho e por fornecer as diretrizes necessárias à minha pesquisa.

Aos professores da instituição Pontifícia Universidade Católica do Rio de Janeiro pela disponibilidade em ajudar, pelos ensinamentos e por toda contribuição durante minha formação acadêmica.

À minha família, especialmente meus pais, pelo amor e apoio incondicionais frente às minhas decisões e por todos os recursos e esforços para minha formação acadêmica, profissional e pessoal.

À minha namorada, Gabriela Duailibe, por todo companheirismo, amor e apoio nessa reta final do curso.

Aos meus colegas e amigos, pelas ótimas lembranças que levarei da minha vida acadêmica na PUC. 


\section{Resumo}

Lima, Matheus Garcia de Andrade. Bittencourt, Andréa. Treinamento Corporativo: repercussão na Empresa X. Rio de Janeiro, 2017. 65 p. Trabalho de Conclusão de Curso - Departamento de Administração. Pontifícia Universidade Católica do Rio de Janeiro.

Esta pesquisa aborda o treinamento corporativo, hoje considerado indispensável nas estratégias das organizações diante da valorização do capital humano na relação com a competitividade. O tema é analisado do ponto de vista histórico e conceitual, de suas vantagens/benefícios versus barreiras/dificuldades, entre elas a questão da ausência de consideração de aspectos humanos e comportamentais nas práticas de treinamento, que resultaria na frustração de expectativas profissionais e pessoais daqueles que são treinados. Realiza-se estudo de caso de uma empresa comparando a percepção de dois grupos sobre os treinamentos realizados: o grupo formado por responsáveis pelos treinamentos da empresa e o grupo de empregados que recebem treinamento.

Palavras- chave

Treinamento corporativo, repercussão na Empresa X.

\section{Abstract}

Lima, Matheus Garcia de Andrade. Bittencourt, Andréa. Corporate Training: repercussion in Company X. Rio de Janeiro, 2017. 65 p. Trabalho de Conclusão de Curso - Departamento de Administração. Pontifícia Universidade Católica do Rio de Janeiro.

This research approaches corporate training, today considered indispensable in the strategies of the organizations against the valorization of the human capital in the relation with the competitiveness. The theme is analyzed from the historical and conceptual point of view, its advantages/benefits versus barriers/difficulties, between them the question of the lack of consideration of human and behavioral aspects in training practices, which would result in the frustration of the professional and personal expectations of those who are trained. A case study of a company is carried out comparing the perception of two groups about the trainings performed: the group formed by those responsible for the training of the company and the group of employees who receive training.

\section{Key-words}

Corporate training, repercussion in Company $\mathrm{X}$. 


\section{Sumário}

1 O tema e o problema de estudo 8

1.1. Introdução ao treinamento corporativo e ao problema do estudo 8

$\begin{array}{ll}\text { 1.2. Objetivos do estudo } & 10\end{array}$

1.3. Delimitação e foco do estudo 10

$\begin{array}{ll}\text { 1.4. Justificativa e relevância } & 10\end{array}$

2 Revisão de literatura $\quad 12$

2.1. Valorização do capital humano nas organizações: foco no $\begin{array}{ll}\text { conhecimento e aprendizagem contínua } & 12\end{array}$

2.2. Gestão de pessoas: para além da administração de recursos $\begin{array}{ll}\text { humanos } & 16\end{array}$

2.3. Treinamento corporativo: aspectos históricos e conceituais 21

2.3.1. Tipos e técnicas de treinamento 26

2.3.2. Treinamentos: vantagens/benefícios, barreiras/dificuldades 30

3 Métodos e procedimentos de coleta e de análise de dados do estudo 34

3.1. Método de pesquisa utilizado 34

3.2. Procedimento e instrumento de coleta de dados 34

3.3. Análise dos dados coletados 35

3.4. Limitações do estudo 35

4 Apresentação e análise dos resultados $\quad 37$

4.1. A Empresa $X \quad 37$

4.2. Respostas dos responsáveis pelos treinamentos e análise $\quad 39$

4.3. Respostas dos empregados e análise 46

5 Conclusões e recomendações para novos estudos 54

6 Referências Bibliográficas 58 


\section{Lista de Figuras}

Figura 1: Os seis processos da gestão de pessoas segundo Chiavenato (2004)

Figura 2: Investimento anual médio em T\&D: Estados Unidos e Brasil ............. 31

Figura 3: Gráfico das vantagens/benefícios dos treinamentos ....................... 40

Figura 4: Gráfico das barreiras/dificuldades dos treinamentos ........................ 41

Figura 5: Gráfico das razões do envolvimento com os treinamentos da Empresa

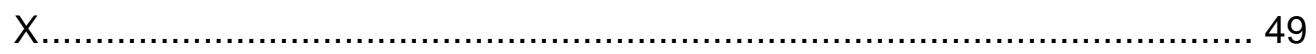

\section{Lista de Tabelas}

Tabela 1: Características da sociedade industrial e da sociedade do conhecimento ........................................................................ 13

Tabela 2: Abordagem tradicional e abordagem atual dos recursos humanos.... 20

Tabela 3: Diferenças entre treinamento e desenvolvimento de pessoas ........... 24

Tabela 4: Dados gerais dos responsáveis pelos treinamentos .......................... 39

Tabela 5: Verdadeiro ou Falso sobre a Empresa X ....................................... 42

Tabela 6: Razões para a Empresa X realizar treinamentos .............................. 43

Tabela 7: Periodicidade dos treinamentos e empregados que abrangem ......... 44

Tabela 8: Dados gerais dos empregados ................................................... 46

Tabela 9: Por que os treinamentos nas instalações da empresa são importantes

Tabela 10: Verdadeiro ou Falso sobre a Empresa $X$................................... 47

Tabela 11: Verdadeiro ou Falso para a percepção dos treinamentos da Empresa

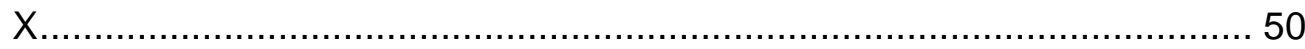




\section{0 tema e o problema de estudo}

\subsection{Introdução ao treinamento corporativo e ao problema do estudo}

Pode-se dizer que o treinamento de pessoas nas empresas tem início no mundo moderno. As primeiras ações nesse sentido surgem na época da Revolução Industrial - iniciada na Inglaterra no século XVIII, sendo marcada pela mecanização da produção e crescimento do trabalho especializado nas fábricas - visando à diminuição de erros na produção e à ampliação da capacidade humana na realização de tarefas. (PILLA, 2002).

No século XX, a partir de 1930, contrapondo o paradigma mecanicista das práticas industriais vigentes, o treinamento ganha maior importância, situação que prevaleceria nas décadas seguintes, quando então passou a ser visto como um evento sistêmico, assim como as demais atividades empresariais. (PILLA, 2002). Ao final deste século, com a emergência do fenômeno conhecido como globalização, verificam-se a intensificação do comércio mundial e o acirramento da concorrência, resultando em um ambiente de alta competitividade entre as organizações.

$\mathrm{Na}$ atualidade, grandes e velozes transformações permeiam a sociedade nos níveis social, político, econômico, tecnológico, científico e empresarial. Diante deste cenário, e no âmbito de maior complexidade interna, as empresas tiveram que mudar seus padrões, seja na gestão administrativa, seja em relação aos meios de produção, mas, principalmente, em relação às pessoas que nelas atuam. (FRESCHI et al., 2006). Isso inclui a redefinição dos sistemas de gestão de recursos humanos, pois o capital humano passou a ser valorizado como fonte de vantagem competitiva.

Segundo Freschi et al. (2006), as mudanças impostas pela globalização colocaram o homem como sujeito ativo neste processo, sendo ele o grande responsável pelo sucesso ou fracasso das organizações. Assim, não basta apenas investir em tecnologia e novos produtos, mas é preciso, sobretudo, investir nas potencialidades humanas a fim de preparar os colaboradores para lidar com as transformações em curso e levar a empresa a um bom posicionamento de mercado. 
Frente à necessidade de as empresas atentarem para as políticas internas de gestão de pessoas, sobretudo, aquelas relacionadas com educação para o trabalho, investir em programas de aprimoramento e capacitação profissional tornou-se condição essencial para a competitividade, garantindo a expansão de espaços de atuação. Especialmente influenciadas pelas mudanças geradas pela globalização, as organizações vêm buscando cada vez mais o melhor desempenho profissional para a sua inserção e manutenção no atual mercado competitivo. (FRESCHI et al., 2006). Daí porque o treinamento corporativo passou a ser relevante, tornando-se parte integrante de suas estratégias. (PILLA, 2002).

De fato, atualmente, grande parte das empresas investe em treinamento corporativo, inclusive para reter profissionais talentosos, um de seus maiores desafios. As empresas norte-americanas, por exemplo, têm investido $80 \%$ mais horas de treinamento formal por colaborador do que a média mundial. No Brasil, onde investimentos em treinamentos formais têm atingido $57 \%$ do orçamento de muitas empresas, investe-se em média 45 horas/ano em treinamento de algum tipo. Em empresas de serviços, tecnologia da informação e consultorias este investimento representa quase o dobro da média nacional, 89 horas/ano. (RISE, 2015).

No entanto, apesar da crescente expansão dos investimentos em treinamento de colaboradores, existem questionamentos a respeito. Um deles, enfocado no presente estudo, refere-se à ausência de consideração e alcance de aspectos humanos nas estratégias de treinamento, entre outros, particularidades pessoais, motivação, reflexão e efetivo aprendizado, e mudança de comportamento. (PILLA, 2002). Como consequência, nem sempre os treinamentos atenderiam às expectativas profissionais e pessoais dos empregados. (GONÇALVES, 2017).

Segundo a literatura, o treinamento tem caráter educacional na medida em que envolve atividades de aprendizagem e educação voltadas ao crescimento pessoal, impulsionando o desenvolvimento da empresa. Deve qualificar o indivíduo em termos de habilidades, conhecimentos e atitudes que resultem na melhoria da adequação entre suas características e as exigências da função que ele ocupa. Além disso, o treinamento deve desempenhar papel integrador entre os participantes para melhorar a socialização Portanto, não pode ser encarado como um processo mecanicista e adestrador. (GONÇALVES, 2017). 
O tema desta pesquisa é o treinamento corporativo. Tendo em vista as colocações iniciais, indaga-se: qual a percepção dos empregados da Empresa $X$ em relação aos treinamentos aplicados pela mesma? A percepção dos responsáveis pelos programas de treinamento da Empresa $X$ é compatível com a percepção dos empregados da mesma sobre suas ações?

\subsection{Objetivos do estudo}

O objetivo central do estudo é identificar como os empregados da Empresa $X$ percebem os treinamentos gerados pela área de recursos humanos e se estes atendem às suas expectativas profissionais e pessoais, evidenciado se a percepção dos responsáveis pelos programas de treinamento da Empresa $X$ é compatível com a percepção dos empregados. São objetivos intermediários:

- Realizar um estudo teórico-conceitual sobre treinamento corporativo a partir das contribuições de autores que escreveram sobre o tema;

- Analisar, à luz da literatura, os impactos do treinamento de pessoal para o desempenho das empresas;

- Refletir sobre a valorização do capital humano nas organizações e a passagem da administração de recursos humanos para a gestão de pessoas.

\subsection{Delimitação e foco do estudo}

O estudo delimita-se à análise da evolução do conceito de treinamento corporativo e das atuais tendências das empresas neste âmbito. O foco recai sobre as políticas de gestão de pessoas da Empresa $X$, aí incluídos os treinamentos por ela realizados no período que vai de 2015 até o presente momento.

\subsection{Justificativa e relevância}

O estudo se justifica pela percepção da necessidade de aprofundamento da discussão sobre treinamentos e, especialmente, sobre a forma como estes vêm sendo realizados pelas empresas. A relevância do estudo se expressa no fato de que, apesar de as empresas virem investindo significativamente em treinamentos formais para seus colaboradores, aspectos humanos, comportamentais, têm sido relegados a um segundo plano. Segundo Pilla 
(2002), a história revela que, nas práticas de capacitação profissional, algumas organizações têm considerado prioritariamente aspectos objetivos, como custos, logística, levantamento das necessidades da empresa, avaliação etc., em detrimento dos aspectos humanos, comportamentais. 


\section{Revisão de literatura}

Este capítulo aborda assuntos que são relevantes para a análise do tema central do trabalho (treinamento corporativo) sob o ponto de vista da literatura. Neste âmbito, analisa-se o contexto que originou a valorização do capital humano nas organizações; a ultrapassagem da ideia de administração de recursos humanos na direção do conceito de gestão de pessoas como uma consequência desta valorização; e o treinamento corporativo em seus aspectos históricos e conceituais. São analisados ainda os diferentes tipos de treinamento, bem como as vantagens, barreiras e dificuldades para a sua implementação nas empresas.

\subsection{Valorização do capital humano nas organizações: foco no conhecimento e aprendizagem contínua}

No livro "Sociedade Pós-Capitalista”, lançado no início da década de 1990, Peter Drucker previu a chegada de um novo momento econômico e com ele um novo modelo de sociedade para o século XXI. (DRUCKER, 2001). Drucker afirmava que o conhecimento se tornaria fonte primária de riqueza, desempenhando papel preponderante em todas as dimensões da vida humana, e que, na sociedade pós-capitalista, ele não poderia ser visto apenas como mais um recurso somado aos tradicionais fatores de produção (terra, força de trabalho e capital), mas o recurso econômico básico e essencial, o único com significado:

\footnotetext{
$\mathrm{Na}$ verdade, o conhecimento é hoje o único recurso com significado. Os tradicionais "fatores de produção" - terra (isto é, recursos naturais), mão de obra e capital - não desapareceram, mas tornaram-se secundários. Eles podem ser obtidos facilmente, desde que haja conhecimento. E 0 conhecimento, neste novo sentido, significa conhecimento como coisa útil, como meio para a obtenção de resultados sociais e econômicos. (DRUCKER, 2001, p. 16-17).
}

O prognóstico de Peter Drucker referia-se à superação da chamada sociedade industrial - marcada por uma economia baseada apenas no capital e trabalho, mecanização nas fábricas e produção em série, formação de grandes entidades industriais e Administração Científica - para a sociedade do 
conhecimento, caracterizada pela economia globalizada, pelo uso extensivo do recurso do conhecimento, informatização da produção e difusão da tecnologia da informação e das telecomunicações. (SANTOS et al., 2007).

$\mathrm{Na}$ Tabela 1 é possível observar as diferenças entre a sociedade industrial e a sociedade do conhecimento por meio das características de uma e de outra.

Tabela 1: Características da sociedade industrial e da sociedade do conhecimento

\begin{tabular}{|c|c|}
\hline Sociedade Industrial & Sociedade do Conhecimento \\
\hline Tecnologia: & Tecnologia: \\
\hline $\begin{array}{l}\text { Energia: óleo, carvão } \\
\text { Materiais: recursos não renováveis } \\
\text { Ferramentas: máquinas } \\
\text { Métodos de Produção: linha de } \\
\text { montagem } \\
\text { Transporte: barco a vapor, ferrovia, } \\
\text { automóvel e avião } \\
\text { Sistema de Comunicação: imprensa, } \\
\text { televisão }\end{array}$ & $\begin{array}{l}\text { Energia: sol, vento e nuclear } \\
\text { Materiais: recursos renováveis } \\
\text { (biotecnologia) } \\
\text { Ferramentas: computadores } \\
\text { Métodos de Produção: robôs } \\
\text { Transporte: espacial } \\
\text { Sistema de } \\
\text { Comunicação: individuais ilimitados } \\
\text { por meios eletrônicos }\end{array}$ \\
\hline Economia: & Economia: \\
\hline $\begin{array}{l}\text { Economia de mercado nacional } \\
\text { Produção: de bens padronizados. } \\
\text { O capital físico é o recurso } \\
\text { fundamental }\end{array}$ & $\begin{array}{l}\text { Economia global integrada } \\
\text { Produção: provisão de serviços } \\
\text { baseados no conhecimento. } \\
\text { O capital humano é o recurso } \\
\text { fundamental }\end{array}$ \\
\hline Sistema social: & Sistema social: \\
\hline $\begin{array}{l}\text { Família nuclear com divisão de } \\
\text { papéis entre os sexos. } \\
\text { Educação: é em massa }\end{array}$ & $\begin{array}{l}\text { O individuo é o centro com diversos } \\
\text { tipos de família e fusão dos papéis } \\
\text { sexuais. } \\
\text { Valores sociais enfatizam a } \\
\text { diversidade, a igualdade e o } \\
\text { individualismo }\end{array}$ \\
\hline Sistema político: & Sistema político: \\
\hline $\begin{array}{l}\text { Capitalismo e marxismo: leis, } \\
\text { religião, classes sociais e políticas } \\
\text { são modeladas de acordo com os } \\
\text { interesses da propriedade e controle } \\
\text { de investimentos } \\
\text { Nacionalismo: forte }\end{array}$ & $\begin{array}{l}\text { Cooperação global: instituições são } \\
\text { modeladas com base na propriedade } \\
\text { e no controle do conhecimento. As } \\
\text { principais unidades de governo e a } \\
\text { democracia participativa definem as } \\
\text { normas }\end{array}$ \\
\hline Paradigma: & Paradigma: \\
\hline $\begin{array}{l}\text { Conhecimento: física e química } \\
\text { Ideias centrais: homens se colocam } \\
\text { como controladores do destino }\end{array}$ & $\begin{array}{l}\text { Conhecimento: eletrônica quântica, } \\
\text { biologia molecular. } \\
\text { ldeias centrais: homens são capazes } \\
\text { de uma transformação contínua e de } \\
\text { crescimento }\end{array}$ \\
\hline
\end{tabular}

FONTE: SANTOS et al. (2007, p. 59). 
Segundo Stewart (2002), conhecimento não é soma, mas agregação, interação e acumulação; dura mais do que a informação. Identificá-lo, captá-lo e organizá-lo gera retorno. Por tal razão, tornou-se o principal elemento daquilo que produzimos, fazemos, compramos e vendemos. Resultado: "administrá-lo encontrar e estimular o capital intelectual, armazená-lo, vendê-lo e compartilhá-lo - tornou-se a tarefa econômica mais importante dos indivíduos, das empresas e dos países". (STEWART, 2002, p. 11).

Para Fitz-Enz (2001), o conhecimento converte dados em informações que são usadas para acelerar todos os ativos de uma organização. Como se trata de algo intrínseco aos seres humanos, relaciona-se aos benefícios que os indivíduos podem proporcionar - expertise, habilidades, atitudes no trabalho, poder de inovação e renovação. (SANTOS et al., 2007; FITZ-ENZ, 2001).

Esta nova realidade levou à crescente valorização do capital humano nas empresas, expressão que remete àquilo que apenas as pessoas podem oferecer (seu intelecto, conhecimentos e experiências). Segundo Chiavenato (2010, p. 53), o capital humano "é o patrimônio inestimável que uma organização pode reunir para alcança a competitividade e o sucesso". Mas ele é um subproduto do capital intelectual, que é mais amplo, abrangendo conhecimentos acumulados, metodologias, patentes, projetos e relacionamentos. (PEREIRA, 2005).

O capital intelectual é o conhecimento que transforma matérias-primas, tornando-as valiosas. Por isso, é um dos ativos intangíveis mais importantes nas organizações contemporâneas. (STEWART, 2002). ${ }^{1}$ Segundo Pereira (2007, p. 39):

\begin{abstract}
A vantagem do capital intangível sobre o tangível é que o primeiro apresenta uma capacidade quase ilimitada de se obter valor adicional, pois cada indivíduo tem uma capacidade infinita de criar, de inovar, desde que esteja em um ambiente adequado para tal desenvolvimento. Os economistas afirmam que os ativos intangíveis, dos quais faz parte o conhecimento, proporcionam às empresas "retornos crescentes de escala", ao contrário do que acontece nas economias tipicamente industriais, onde as empresas obtêm "retornos decrescentes de escala".
\end{abstract}

Certas empresas, chamadas empresas do conhecimento, conseguem implementar um ambiente propício à criação de conhecimento. Elas possuem estruturas voltadas para a inovação e enfatizam a capacidade de ação

\footnotetext{
${ }^{1}$ Segundo Pereira (2007, p. 39), ativos intangíveis são entendidos como tudo o que cria valor e crescimento para uma empresa, mas que não é um ativo físico, como: ideias, marcas, formas de trabalhar, o conhecimento de funcionários etc.
} 
intelectual de seus empregados. Nessas empresas, o valor do capital intelectual é muito maior do que o valor de outros ativos, principalmente os ativos fixos: quanto menos ativos melhor, desde que haja capital intelectual. (STEWART, 2002). Outra característica desse tipo de empresa é que elas requerem aprendizado constante de seus colaboradores favorecendo a capacidade coletiva de aprender. (FITZ-ENZ, 2001).

As learning organizations, ou organizações que aprendem - termo cunhado pelo autor Peter Senge no livro "A Quinta Disciplina" - são baseadas no conhecimento e caracterizadas como mais flexíveis, mais adaptáveis, mais inovadoras e capazes de se reinventar porque promovem o desenvolvimento e a expansão do conhecimento em todo o seu interior. (RICHIE e MONTE ALTO, 2001).

São formadas por pessoas que expandem, continuamente, a sua capacidade de criar os resultados que desejam, onde se estimulam padrões de comportamento novos e abrangentes, a aspiração coletiva ganha liberdade, e as pessoas exercitam-se, continuamente, em aprender juntas. (RICHIE e MONTE ALTO, 2001, p. 37).

Este modelo de empresa, no entanto, não é de fácil construção. Para que ele exista, é preciso antes de tudo que se estabeleça uma cultura organizacional eficaz, baseada em cinco disciplinas que devem funcionar em conjunto, de acordo com Peter Senge, conforme a seguir:

1. Domínio pessoal - correspondente ao fortalecimento da capacidade individual de aprendizagem, pois só assim se pode chegar ao conhecimento organizacional. O domínio pessoal vai além das competências e habilidades pessoais: "[...] sugere um dado nível de proficiência em todos os aspectos da vida, pessoal e profissional". (RICHIE e MONTE ALTO, 2001, p. 49);

2. Novos modelos mentais - para combater ideias e paradigmas antiquados que interferem negativamente nas atitudes das pessoas. Esses novos modelos incluem mudanças administrativas que ajudam os colaboradores a reconhecer novas ideias para que tomem consciência de sua influência sobre seus atos;

3. Visão compartilhada - relacionada à missão genuína da empresa no sentido de as pessoas darem o melhor de si e adotarem o compartilhamento, com compromisso e comprometimento. A visão compartilhada "é vital para a organização que aprende porque 
proporciona foco e energia”. (RICHIE e MONTE ALTO, 2001, p. $51)$;

4. Aprendizado em equipe - a aprendizagem nas empresas é do grupo, e não de indivíduos isoladamente. O aprendizado em equipe requer a reformulação da prática do diálogo e da discussão, buscando alinhar e desenvolver a capacidade dos grupos na criação dos resultados que seus membros realmente desejam alcançar. (RICHIE e MONTE ALTO, 2001);

5. Pensamento sistêmico - que integra todas as disciplinas anteriores como um elo de ligação. Ele ensina a ver o todo e ajuda as pessoas a enxergar as coisas como parte de um todo, e não como peças isoladas. Sua essência consiste em proporcionar mudança de mentalidade a partir de inter-relacionamentos. (RICHIE e MONTE ALTO, 2001).

\subsection{Gestão de pessoas: para além da administração de recursos humanos}

Tradicionalmente, no contexto da Administração de Recursos Humanos $(\mathrm{ARH})$, o trabalho dos departamentos voltados aos colaboradores das empresas caracterizou-se por tarefas operacionais e burocráticas, entre elas, recrutamento, seleção, treinamento, controle e avaliação de pessoal. No entanto, a mudança no ambiente de negócios ocorrida a partir das últimas décadas do século $\mathrm{XX}$ impôs reformulações nesse modelo. Segundo Antunes et al. (2000), principalmente em decorrência:

- Da necessidade de as empresas obterem vantagem competitiva por meio da diferenciação e da qualidade de serviços e produtos, vantagem essa dependente da qualidade e comprometimento de seus colaboradores;

- Da exigência de redução de custos, incluindo seleção mais cuidadosa de pessoal, obtenção de menor índice de turnover (rotatividade de empregados) e de absenteísmo (faltas), além de controles mais reduzidos;

- Da imposição de mudança nas relações com os colaboradores, uma vez que um novo clima no ambiente de trabalho com redução do controle burocrático passou a ser visto como favorecedor de inovação; 
- Da exigência de melhoria na imagem da empresa através de novas práticas no gerenciamento de pessoal, que passaram a ser vistas como vantagens no mercado (expressando responsabilidade social e correta atração de colaboradores de alta qualificação ou com potencial para tanto);

- Das falhas da administração convencional de RH e ineficácia dos departamentos do setor na implementação de inovações e de novas políticas de pessoal, que questionaram a sua contribuição efetiva para a obtenção de vantagem competitiva;

- Da necessidade de as empresas implementarem modelos de excelência no setor de $\mathrm{RH}$ devido aos impactos positivos desses modelos na competitividade das grandes companhias. (ANTUNES et al., 2000).

Esses fatores, por si só, evidenciaram que a tradicional administração de recursos humanos precisava reorientar-se em suas práticas e funções. (ANTUNES et al., 2000). A progressiva tendência à valorização do conhecimento e aprendizado organizacional contínuo acirrou esse processo e elevou o papel das pessoas nas empresas, fato identificado por diferentes autores.

Na década de 1990, Sveiby (1998, p. 9) já afirmava que as pessoas eram os únicos verdadeiros agentes das empresas, consistindo em trabalhadores do conhecimento, pois reúnem um conjunto de capacidades, competências e aptidão para a aprendizagem. Esse autor identificava a crescente importância das pessoas argumentando que os ativos e estruturas tangíveis e intangíveis das organizações são resultados das ações humanas. "Todos dependem das pessoas, em última instância, para continuar a existir"; as máquinas apenas complementam a capacidade do ser humano. (SVEIBY, 1998).

Fitz-Enz (2001, p. 1) afirma que:

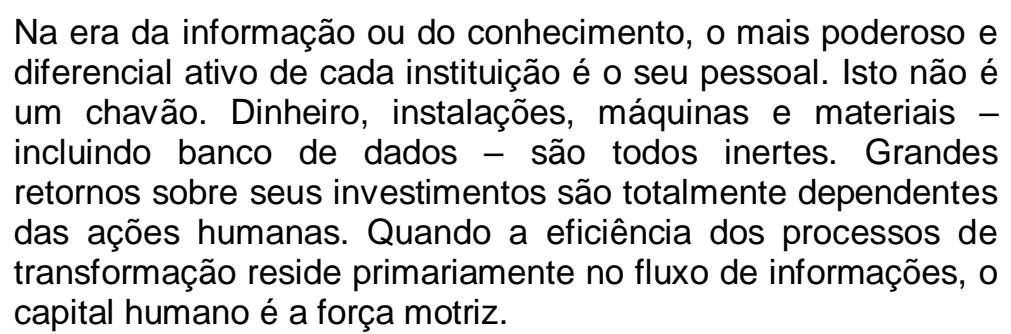

De acordo com Mair (2005): 
Os recursos humanos são o "first value" de uma empresa e constituem, portanto, o fator decisivo para se impor em uma economia baseada em conhecimento e em prestação de serviços. O funcionário já não é apenas o meio para um fim, cujo desempenho é necessário para o processo de trabalho, mas é o ponto central. É nele que devemos confiar, é ele quem deve ser encorajado. (MAIR, 2005, p. 17).

A valorização dos indivíduos nas empresas foi também identificada por Boog (2001), que defendeu uma profunda modificação na forma tradicional de gerenciar pessoas nas organizações. Para esse autor:

Se focalizarmos a ação que por décadas vem sendo conduzida por $\mathrm{RH}$ nas empresas, podemos ver a distância que separa essa ação dos novos paradigmas. O próprio nome Recursos Humanos revela-se pouco adequado, pois denota um foco "utilitário" das pessoas (quem gosta de ser um recurso humano?), devendo ser substituído por Talentos Humanos, Pessoas, Potencial Humano, Seres Humanos ou outros termos assemelhados. (BOOG, 2001, p. 10).

A partir de então, a visão mecanicista do setor de recursos humanos situada no nível operacional e burocrático, e desenvolvida por meio de atividades que se limitam à garantia de condições de trabalho aos empregados, eximindo-se do foco em conhecimentos, habilidades e competências - foi ultrapassada. (BOOG, 2001). A nova concepção sobre a gestão de recursos humanos voltou-se para a valorização da participação dos colaboradores nas empresas, expressando-se no conceito de gestão de pessoas, que modificou dimensões culturais e comportamentais nas organizações. (CHIAVENATO, 2010).

Gil (apud DUTRA, 2009) afirma que a gestão de pessoas é um ramo especializado da ciência da administração que contempla todas as ações empreendidas por uma organização com o objetivo de integrar o colaborador no contexto da organização e aumentar sua produtividade. Já para Dutra (2009, p. 21), a gestão de pessoas é um conjunto de políticas e práticas "que permitem a conciliação de expectativas entre a organização e as pessoas para que ambas possam realizá-las ao longo do tempo".

Chiavenato (2010, p. 9) define gestão de pessoas como a função que "permite a colaboração eficaz das pessoas - empregados, funcionários, recursos humanos ou qualquer denominação utilizada - para alcançar os objetivos organizacionais e individuais". E afirma que esta abordagem é composta por um conjunto integrado de seis processos dinâmicos e interativos. (CHIAVENATO, 2004). 
1. Processos de agregar pessoas - relativos à provisão de pessoas na empresa, que inclui recrutamento e seleção;

2. Processos de aplicar pessoas - voltados à integração das pessoas selecionadas em termos de cargos e tarefas e avaliação de seu desempenho;

3. Processos de recompensar pessoas - referentes à remuneração, benefícios e incentivos que motivam os colaboradores;

4. Processos de desenvolver pessoas - utilizados para capacitar os colaboradores tanto em relação à sua área de atuação quanto em relação a posições futuras. Envolvem treinamento e mudanças;

5. Processos de manter pessoas - envolvem a criação de um ambiente que satisfaça e motive os colaboradores, incluindo aspectos de saúde e qualidade de vida na organização;

6. Processos de monitorar pessoas - voltados ao acompanhamento e controle das atividades que estão sendo desenvolvidas, a fim de verificar seus resultados. Dependem de banco de dados e sistemas de informações gerenciais. (CHIAVENATO, 2004).

A Figura 1 detalha os seis processos da gestão de pessoas.

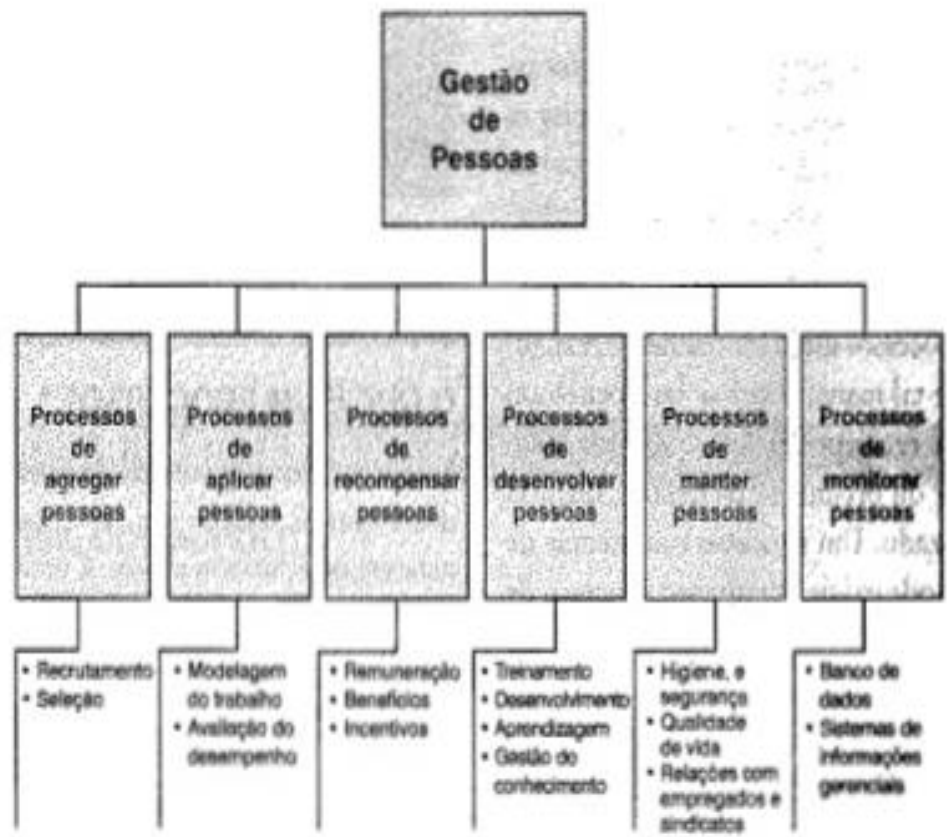

Figura 1: Os seis processos da gestão de pessoas segundo Chiavenato (2004) FONTE: CHIAVENATO (2004, p. 15).

Segundo Chiavenato (2010), a abordagem da gestão de pessoas se baseia em três pontos: 1) pessoas são seres humanos dotados de 
personalidade, e não mero recurso material da empresa; 2) pessoas são agentes que impulsionam o desenvolvimento do capital intelectual e de outros recursos das organizações; e 3) pessoas são parceiros ativos da organização. Por isso, estudos organizacionais mais recentes sobre gestão de pessoas vêm abordando aspectos humanos nas empresas - tais como particularidades individuais, sentimentos, interações, motivação, mudança de comportamento, participação, reflexão e aprendizado, entre outros - para que objetivos organizacionais estratégicos possam ser atingidos, bem como objetivos pessoais e profissionais de auto-realização. (PILLA, 2002).

Esse fundamento permite observar as diferenças entre a visão das pessoas como recursos organizacionais e a visão das pessoas como parceiros das organizações, conforme proposto por Chiavenato (2010). A Tabela 2 sintetiza essas diferenças.

Tabela 2: Abordagem tradicional e abordagem atual dos recursos humanos

\begin{tabular}{|c|c|}
\hline Pessoas como recursos & Pessoas como parceiros \\
\hline Empregados isolados nos cargos & $\begin{array}{c}\text { Colaboradores agrupados em } \\
\text { equipes }\end{array}$ \\
\hline $\begin{array}{c}\text { Funcionários que obedecem a } \\
\text { horários rigidamente estabelecidos }\end{array}$ & Metas negociadas e compartilhadas \\
\hline Preocupação com regras e normas & Preocupação com resultados \\
\hline Empregados subordinados à chefia & $\begin{array}{l}\text { Énfase no atendimento e satisfação } \\
\text { do cliente }\end{array}$ \\
\hline Empregados fiéis à organização & $\begin{array}{l}\text { Colaboradores vinculados à missão e } \\
\text { à visão da empresa }\end{array}$ \\
\hline Funcionários dependentes da chefia & $\begin{array}{l}\text { Colaboradores interdependentes de } \\
\text { colegas e equipes de trabalho }\end{array}$ \\
\hline $\begin{array}{l}\text { Funcionários alienados em relação à } \\
\text { empresa }\end{array}$ & $\begin{array}{l}\text { Ênfase na participação e no } \\
\text { comprometimento }\end{array}$ \\
\hline Ênfase na especialização & $\begin{array}{l}\text { Ênfase na ética e na } \\
\text { responsabilidade }\end{array}$ \\
\hline $\begin{array}{c}\text { Empregados como executores de } \\
\text { tarefas }\end{array}$ & $\begin{array}{l}\text { Colaboradores são fornecedores de } \\
\text { atividades }\end{array}$ \\
\hline Ênfase em destrezas manuais & Énfase no conhecimento \\
\hline $\begin{array}{l}\text { Empregados vistos como mão-de- } \\
\text { obra }\end{array}$ & $\begin{array}{l}\text { Colaboradores são vistos na sua } \\
\text { inteligência e talento }\end{array}$ \\
\hline
\end{tabular}

FONTE: CHIAVENATO (2010, p.9).

A gestão de pessoas enfatiza aspectos intangíveis, como o aprendizado, o conhecimento, habilidades, competências e aprendizagem coletiva, que hoje são reconhecidos como elementos que efetivamente contribuem com maior peso para o alinhamento das funções do $\mathrm{RH}$ com a estratégia organizacional. Esse foco também leva ao reconhecimento da importância dos laços humanos, da 
interação social e convivência entre os indivíduos que compõem a organização, propiciando um ambiente capaz de resultar em satisfação profissional e pessoal. O treinamento, tema da próxima seção da pesquisa, se enquadra nesse contexto, reforçando todos esses aspectos. (GONÇALVES, 2017).

\subsection{Treinamento corporativo: aspectos históricos e conceituais}

Segundo Carvalho (apud AMARAL, 2014), o aprendizado contínuo e integral do indivíduo é processado por meio de três fatores:

1. Educação, que é a reconstrução contínua da experiência individual por toda a vida;

2. Instrução, que corresponde à formalização do processo educacional em seus vários graus; e

3. Treinamento, cuja finalidade principal é proporcionar ao indivíduo um desempenho adequado às suas atividades.

$O$ verbo treinar vem do francês trainer e significa exercitar, praticar. $O$ substantivo treinamento é formado pelos vocábulos treinar + mentor, onde mentor é a pessoa que aconselha, ensina ou guia alguém a fazer algo. (AMARAL, 2014). "Treinar é então levar alguém a ser capaz de fazer algo que ele nunca fez antes, e fazê-lo sem a assistência de quem ensina". (PILLA, 2002, p. 33-34).

No âmbito empresarial, o termo passou a ser utilizado referindo-se ao processo de preparar pessoas para a execução de tarefas exigidas por um posto de trabalho definido por quem projetou/organizou a empresa. (PILLA, 2002). Frederick Winslow Taylor $^{2}$ é considerado o pai do treinamento, pois teria sido o primeiro grande administrador a se preocupar com a execução de atividades laborais com eficiência, eliminando as variáveis do processo e buscando maior produtividade dos trabalhadores. (AMARAL, 2014).

Boog (2001) define treinamento como o processo voltado a desenvolver e promover conhecimento, habilidade e comportamento para atender a requisitos. Justifica-se mediante a necessidade de eliminar a diferença entre o nível atual de eficiência e aquele desejado.

2 O engenheiro norte-americano Frederick W. Taylor (1856-1915) é considerado o precursor da chamada Administração Científica do trabalho, bem como da aplicação de seus princípios e técnicas. Implementou um modelo de administração organizacional, denominado taylorismo, baseado na racionalidade econômica. 
Para Chiavenato (2008, p. 402), treinamento é o processo educacional de curto prazo, aplicado de maneira sistemática e organizada, "através do qual as pessoas aprendem conhecimentos, habilidades e competências em função de objetivos definidos".

[...] é o processo de desenvolver qualidades nos recursos humanos, para habilitá-los a serem mais produtivos e contribuir melhor para o alcance dos objetivos organizacionais. $O$ propósito do treinamento é aumentar a produtividade dos indivíduos em seus cargos, seus comportamentos. (CHIAVENATO, 2004, p. 339).

Em termos históricos, o treinamento passou por três fases distintas. $\mathrm{Na}$ primeira, enfatizava o homem-objeto, concebido meramente como instrumento, e, neste âmbito, tinha na produtividade o seu objetivo principal. "Aqui o indivíduo não tinha identificação com a organização, considerado um equipamento sofisticado. O treinamento neste período era uma espécie de adestramento". (GONÇALVES, 2017, p. 2).

$\mathrm{Na}$ segunda fase, o ser humano era visto como um recurso adicional e, neste período, a maior preocupação do treinamento era com o aprimoramento de habilidades. Contando com a integralização do indivíduo com a organização, o treinamento ainda era centrado na produtividade e desenvolvido através de políticas que consideravam apenas as necessidades da empresa ou de um grupo, e não do indivíduo. (GONÇALVES, 2017).

$\mathrm{Na}$ terceira e presente fase, o treinamento muda de concepção - devido à visão do homem como um indivíduo complexo, capaz de expressar atitudes e comportamentos em sua totalidade social, política, familiar e profissional, de maneira crítica e reflexiva - passando a ser visto como um processo que faz parte do desenvolvimento e aprendizagem contínua das pessoas, tornando-se uma via para que as empresas alcancem suas metas e seus objetivos. (GONÇALVES, 2017).

De fato, segundo Chiavenato (2010), de um processo que foi visto como uma preparação de pessoas para o desempenho excelente de tarefas específicas do cargo, o treinamento passou a ser considerado como um meio de desenvolver competências, criatividade e inovação a fim de contribuir para os objetivos organizacionais.

Para o indivíduo que recebe, o treinamento consiste em uma experiência aprendida que produz uma mudança relativamente permanente, melhorando sua capacidade de desempenhar um cargo na empresa. (CHIAVENATO, 2010). 
Visto em geral como o desenvolvimento de qualidades que habilitam as pessoas a serem mais produtivas e melhor contribuírem para o alcance dos objetivos organizacionais, o treinamento pode envolver uma mudança de habilidades, conhecimento, atitudes ou comportamento. "Isso significa mudar aquilo que os empregados conhecem, como eles trabalham, suas atitudes perante o seu trabalho ou suas interações com os colegas ou supervisor". (CHIAVENATO, 2010, p. 339).

O treinamento difere do desenvolvimento de pessoas, embora ambos constituam processos de aprendizagem e se complementem. Segundo Milkovich e Boudreau (2006, p. 338):

\begin{abstract}
Treinamento é um processo sistemático para promover a aquisição de habilidades, regras, conceitos ou atitudes que resultem em uma melhoria da adequação entre as características dos empregados e as exigências dos papéis funcionais. Desenvolvimento é o processo de longo prazo para aperfeiçoar as capacidades e motivações dos empregados a fim de torná-los futuros membros valiosos da organização.
\end{abstract}

$\mathrm{Na}$ visão desses autores, o treinamento tem função técnico-operacional enquanto o desenvolvimento possui função mais estratégica para as organizações, pois inclui, além do treinamento, plano de carreira e outras experiências visando ocupações de cargos no longo prazo. (MILKOVICH e BOUDREAU, 2006).

Chiavenato (2010) menciona o fator tempo como uma das diferenças: enquanto o treinamento é orientado para o presente, para o curto prazo, focalizando a melhoria de habilidades, conhecimento e atitudes para 0 desempenho imediato de um cargo atual - o desenvolvimento orienta-se para o futuro, para o médio e longo prazos, focando novas habilidades e capacidades que serão necessárias para o preenchimento de cargos futuros na empresa.

O desenvolvimento de pessoas está mais relacionado com a educação e a orientação para o futuro do que o treinamento. Por educação queremos significar as atividades de desenvolvimento pessoal que estão relacionadas com os processos mais profundos de formação de personalidade e da melhoria da capacidade de compreender e interpretar 0 conhecimento, do que com a repartição de um conjunto de fatos e informações a respeito de habilidades motoras ou executoras. O desenvolvimento está mais focalizado no crescimento pessoal do empregado e visa à carreira futura e não apenas o cargo atual. (CHIAVENATO, 2010, p. 409). 
Boog (apud AMARAL, 2014), por sua vez, estabelece as diferenças entre treinamento e desenvolvimento a partir de seis variáveis, conforme se observa na Tabela 3.

Tabela 3: Diferenças entre treinamento e desenvolvimento de pessoas

\begin{tabular}{|c|c|c|}
\hline & Treinamento & Desenvolvimento \\
\hline DEFINIÇÃO & $\begin{array}{c}\text { Processo de efetuar } \\
\text { mudanças no } \\
\text { comportamento do } \\
\text { indivíduo, aplicado na } \\
\text { aquisição de habilidades } \\
\text { relacionadas à sua } \\
\text { tarefa }\end{array}$ & $\begin{array}{c}\text { Processo de crescimento } \\
\text { integral do homem, que } \\
\text { expande a sua habilidade } \\
\text { em utilizar totalmente } \\
\text { suas capacidades e } \\
\text { aplicar seu conhecimento } \\
\text { e experiência para a } \\
\text { solução ou resolução } \\
\text { de novas ou diferentes } \\
\text { situações }\end{array}$ \\
\hline OBJETIVO & $\begin{array}{c}\text { Suprir habilidades, } \\
\text { conhecimentos e } \\
\text { atitudes necessárias } \\
\text { para desempenhar } \\
\text { tarefas } \\
\text { específicas, dentro do } \\
\text { padrão de produtividade } \\
\text { estabelecido }\end{array}$ & $\begin{array}{c}\text { Suprir habilidades, } \\
\text { conhecimentos e atitudes } \\
\text { específicas para o } \\
\text { desempenho de tarefas } \\
\text { futuras, } \\
\text { em um processo de } \\
\text { crescimento contínuo }\end{array}$ \\
\hline ENFOQUE & $\begin{array}{l}\text { Corretivo, atendendo às } \\
\text { necessidades da tarefa } \\
\text { ou cargo atual. Meio de } \\
\text { resolver algum problema }\end{array}$ & $\begin{array}{c}\text { Preventivo, atendendo às } \\
\text { necessidades e potencial } \\
\text { do indivíduo, conforme } \\
\text { tarefa/cargo futuro. Meio } \\
\text { de evitar o aparecimento } \\
\text { de algum problema }\end{array}$ \\
\hline RESPONSABILIDADE & $\begin{array}{c}\text { Da empresa, por meio } \\
\text { de todos os níveis de } \\
\text { chefia, } \\
\text { assessorados pelo } \\
\text { órgão de treinamento }\end{array}$ & $\begin{array}{l}\text { Da empresa, por meio de } \\
\text { todos os níveis de chefia, } \\
\text { assessorados pelo órgão } \\
\text { de treinamento }\end{array}$ \\
\hline $\begin{array}{l}\text { RESULTADO } \\
\text { ESPERADO }\end{array}$ & $\begin{array}{c}\text { Pessoas que } \\
\text { desempenham tarefas } \\
\text { específicas, } \\
\text { atendendo aos padrões } \\
\text { de produtividade, de } \\
\text { maneira a realizar metas } \\
\text { pré-estabelecidas }\end{array}$ & $\begin{array}{l}\text { Pessoas preparadas para } \\
\text { ocupar os cargos-chave } \\
\text { dentro da organização, na } \\
\text { qualidade, quantidade } \\
\text { e época necessárias }\end{array}$ \\
\hline TEMPO & Curto prazo & Médio/longo prazos \\
\hline
\end{tabular}

FONTE: AMARAL (2014, p. 28).

Idealmente, o treinamento corporativo deve ser entendido como um processo sistemático, organizado e cíclico, dado seu caráter educacional. Segundo Boog (2001), ele deve ter numa abordagem sistêmica, que, sendo 
adotada, evidencia um processo composto por quatro etapas ou fases distintas, todas interligadas e igualmente relevantes, a saber:

1. Diagnóstico ou identificação da necessidade do treinamento etapa em que a empresa, a partir de informações precisas e consistentes sobre si mesma (mercado em que está inserida, clientes etc.) faz um levantamento das demandas que podem levar à prática do treinamento, sejam elas relacionadas à estratégia organizacional, a objetivos específicos ou mesmo problemas, entre outros aspectos. O diagnóstico permite a definição clara sobre se as demandas poderão ser solucionadas através do treinamento;

2. Desenho ou elaboração do programa de treinamento - fase em que a empresa planeja ações de treinamento de modo a atender às necessidades identificadas, a partir de prioridades. O desenho permite a tomada de decisões estratégicas sobre: para que treinar, qual o segmento a ser treinado, quem será treinado, em que época, quem vai treinar, onde treinar, que recursos (internos e externos) serão necessários para as ações de treinamento, que investimento será necessário para a realização do treinamento;

3. Implementação ou execução do treinamento - fase intimamente relacionada ao planejamento das ações de treinamento e imediata à aprovação da realização do treinamento pela empresa, que corresponde à aplicação prática e condução do programa, que tanto pode ser realizada pelo departamento de recursos humanos da empresa quanto por empresas terceirizadas. A implementação inclui o estabelecimento de responsabilidades, qualificação de instrutores, identificação de equipamentos e produção de materiais necessários, além da divulgação do programa;

4. Avaliação do treinamento - que vai desde o diagnóstico até a implementação. Esta fase inclui monitoramento do andamento do processo e avaliação da utilização dos recursos empregados no treinamento e de seus resultados, isto é, se o treinamento atendeu a seus objetivos e se produziu resultados positivos em termos financeiros e de mudanças efetivas por meio do aprendizado. A fase de avaliação mede o grau de congruência entre o que era esperado e o que foi efetivamente conquistado e permite que a empresa faça projeções futuras quanto à continuidade dos processos de melhoria. (CHIAVENATO, 2010; BOOG, 2001). 
Tais etapas devem ser percorridas independentemente do tipo de treinamento que a empresa pretende realizar. No entanto, para maior efetividade do treinamento, este deve inserir-se nas políticas globais da organização (aí incluída a política de gestão) e contar com o engajamento da alta hierarquia, bem como de todos os outros membros da empresa. $O$ treinamento deve ter ainda um caráter de continuidade, estando inserido em políticas de educação continuada, possibilitando assim maior desenvolvimento dos colaboradores. (FRESCHI et al., 2006).

\subsubsection{Tipos e técnicas de treinamento}

Macian (apud GONÇALVES, 2017) distingue quatro tipos de treinamentos aplicados nas organizações, de acordo com os resultados do diagnóstico das necessidades de treinamento (primeira fase do emprego do treinamento), a população a ser atingida e a finalidade: treinamento de integração, treinamento técnico-operacional, treinamento gerencial e treinamento comportamental.

O treinamento de integração - que Milkovich e Boudreau (2006) denominam treinamento de orientação - é realizado nos casos de ingresso de empregados novos na empresa. Voltado para a ambientação/adaptação do colaborador, é considerado um treinamento inicial, que inclui informações precisas sobre a instituição, como por exemplo: cultura da organização, estrutura da organização, negócio principal e ramos de negócios, objetivos da organização, práticas e políticas, número de empregados da empresa, setor de trabalho do recém-chegado, colegas com quem ele irá atuar, público com o qual terá contato, benefícios oferecidos, questões de segurança e higiene de trabalho. (GONÇALVES, 2017).

Ou seja, o treinamento de integração funciona como um programa introdutório para que o novo colaborador tenha uma visão geral da empresa tais como normas, regulamentos, procedimentos - e sobre o cargo que irá ocupar, com vistas à sua socialização e aculturação. (GONÇALVES, 2017).

Segundo Chiavenato (2004, p. 177-178):

O programa de integração é destinado aos novos membros da organização para familiarizá-los com a linguagem usual da organização, com os usos e costumes internos (cultura organizacional), a estrutura da organização (áreas ou departamentos existentes), os principais produtos ou serviços, a missão da organização e os objetivos organizacionais. $O$ 
programa ou treinamento de integração constitui o principal método de aculturamento dos novos participantes às práticas correntes da organização.

A finalidade do treinamento de integração é fazer com que o novo participante aprenda e incorpore valores, normas e padrões de comportamento que a organização considera imprescindíveis e relevantes para o bom desempenho de seus empregados. (CHIAVENATO, 2010). Suas vantagens são: redução da ansiedade das pessoas, redução da rotatividade, economia de tempo, ajustamento das expectativas e socialização. (CHIAVENATO, 2004).

De acordo com Chiavenato (2010), a socialização organizacional constitui o esquema de recepção e de boas-vindas aos novos participantes, representando uma etapa de iniciação particularmente importante para moldar um bom relacionamento a longo prazo entre o indivíduo e a organização. Funciona como elemento de fixação e manutenção da cultura organizacional. Os treinamentos de integração são programas que duram de um a cinco dias, dependendo da intensidade de socialização que a empresa pretende imprimir. Nos casos em que o novo colaborador venha a ocupar uma posição de destaque, em níveis de gerência ou direção, esse tipo de treinamento pode durar meses, contando com uma agenda que atinge diversas áreas ou departamentos, um tutor permanente e um específico para cada área ou departamento envolvido na agenda.

O treinamento técnico-operacional em geral é ofertado para colaboradores que atuam em funções operacionais, sendo em geral comandado por empregados mais experientes, que treinam o indivíduo em situações reais de trabalho. Esse tipo de treinamento é voltado para a capacitação do colaborador em termos de informações técnicas sobre suas funções e responsabilidades no cargo, bem como para a assimilação de habilidades operacionais que são relevantes para o desempenho de tarefas específicas da categoria profissional a que ele pertence. (MILKOVICH e BOUDREAU, 2006; GONÇALVES, 2017).

Encarado como um treinamento do "como fazer", o treinamento técnicooperacional consiste em um meio de alcançar as metas previamente estabelecidas pela empresa, impulsionando a produtividade em curto prazo, englobando informações técnicas para o melhor aproveitamento e desenvolvimento de habilidades operacionais. (GONÇALVES, 2017).

Voltado ao desenvolvimento de competências administrativas, o treinamento gerencial (ou de habilidades gerenciais) é aplicado a colaboradores que exercem cargos de chefia, gerentes ou executivos, indicados para 
treinamento com base nas necessidades de competências específicas que guiarão os próximos passos de suas carreiras na empresa - nas grandes corporações o treinamento gerencial está relacionado a um plano sucessório. (MILKOVICH e BOUDREAU, 2006).

Esse tipo de treinamento oferece aos colaboradores desse nível organizacional conhecimentos através da história empresarial que os tornarão mais preparados para representar a empresa e estabelecer visões futuras sobre a mesma, a fim de que ela alcance o desempenho almejado. Sua vantagem reside no enriquecimento de gerentes e executivos em termos de fomento à criatividade para soluções, além do espírito inovador, que, juntos, acionam nos subordinados o desempenho produtivo que deles se espera, baseado no potencial de cada um. (GONÇALVES, 2017).

Já o treinamento comportamental, é voltado para estruturar de maneira adequada a melhoria das relações humanas (eventualmente solucionando conflitos de relacionamento no ambiente de trabalho), da comunicação e das habilidades intra e interpessoal no ambiente de trabalho. (GONÇALVES, 2017). Sua finalidade é mudar atitudes e despertar consciência sobre a importância dessa mudança para a obtenção de melhor relacionamento entre as pessoas e de seus resultados em termos organizacionais. (CHIAVENATO, 2010).

\begin{abstract}
Com o objetivo de reduzir as dificuldades existentes no ambiente corporativo, possibilitando situações cujas percepções possam distorcer os fatos, bem como prejudicar o ambiente de trabalho, as empresas realizam treinamentos comportamentais tendo em vista a importância da conscientização da atitude adequada ao ambiente empresarial; a manutenção do clima organizacional; o bom convívio diário com os colegas, clientes, superiores hierárquicos; a apresentação pessoal; dentre outras. (COSTA e SANTANA, 2013, p. 180).
\end{abstract}

Segundo Gonçalves (2017), na aplicação do treinamento comportamental, convém que se tenha em mente a ocorrência de dificuldades que são inerentes aos relacionamentos e convivência humana, e que, inclusive, reduzem as expectativas sobre os resultados desse tipo treinamento. Por isso, para que o treinamento comportamental seja trabalhado, é preciso buscar conhecimentos de ciências sociais e comportamentais, como a Sociologia e a Psicologia, que podem oferecer subsídios para que os resultados sejam satisfatórios ou menos frustrantes.

Nesse contexto, certos temas que impactam positivamente na mudança de atitude no ambiente de trabalho - por possibilitar às pessoas a ampliação de 
conhecimentos que facilitam o reconhecimento de suas dimensões humanas, que, por sua vez, as conduzem à reflexão - são preferencialmente tratados nos treinamentos comportamentais, por exemplo:

- Inteligência emocional - capacidade de a pessoa reconhecer seus próprios sentimentos e emoções, e o das outras pessoas, para desenvolver a capacidade de lidar com elas nas diversas situações nas quais se encontra cotidianamente;

- Comunicação - no qual busca-se analisar a interferência dos processos subjetivos na transmissão e na decodificação das mensagens, em suas diversas formas de comunicação;

- Administração de conflitos - que capacita para o entendimento de comunicação truncada, falta de empatia e flexibilidade, aliada ao egocentrismo, fatores favoráveis à geração de situações conflituosas, incidentes ou reincidentes, nos mais diversos ambientes onde as pessoas se encontram. (COSTA e SANTANA, 2013, p. 183).

Todos os tipos de treinamento aqui mencionados podem ser congregados, sendo que a empresa pode enfatizar este ou aquele, de acordo com os propósitos estabelecidos. Para colocá-los em prática, diferentes técnicas são utilizadas nos treinamentos, que podem ocorrer tanto internamente, no local de trabalho quanto externamente (fora ambiente de trabalho).

Com base na literatura (BOOG, 2001; PILLA, 2002; MILKOVICH e BOUDREAU, 2006) citam-se, dentre essas técnicas: treinamento em tarefas realizadas no local de trabalho; treinamento em grupos (no ambiente de trabalho ou fora dele); treinamento por rodízio de cargos (também no ambiente de trabalho); aulas expositivas (que podem empregar recursos audiovisuais); leituras; estágios; palestras; workshops; seminários; conferências e cursos presenciais; jogos (cooperativos, e não competitivos); simulações; dinâmicas e discussões em grupo; estudos de caso; dramatizações.

Outas técnicas de treinamento utilizam recursos tecnológicos, tais como: instrução assistida pela informática (através de banco de dados, comunicação on-line); multimídia; videoconferências; instrução baseada na internet, possibilitando treinamento à distância (ou e-learning); treinamento por meio de laboratório virtual, livro eletrônico, e-mail, chats, sites.

Todas essas técnicas de treinamento são voltadas à aprendizagem do treinando, visando ao seu melhor desempenho no âmbito empresarial, bem 
como à sua conscientização sobre a importância do conhecimento tanto para a organização quanto para si mesmo.

\subsubsection{Treinamentos: vantagens/benefícios, barreiras/dificuldades}

A literatura relata vantagens e benefícios dos treinamentos, tanto para o indivíduo quanto para a organização. Para Freschi et al. (2006), por exemplo, o treinamento orienta experiências de aprendizagem num sentido positivo e benéfico fazendo com que todos os indivíduos, em todos os níveis da organização, possam desenvolver conhecimentos, habilidades e atitudes que serão importantes para o seu autodesenvolvimento.

De fato, para os empregados, o treinamento é uma grande oportunidade de se autodesenvolver, de evoluir, de se transformar e repensar padrões e modelos cristalizados (estendendo seus limites), o que representa o aumento de chances de atuação profissional. (FRESCHI et al., 2006). Segundo Amaral (2014, p. 19), "quando a organização investe no colaborador, ele passa a se sentir elemento fundamental para o sucesso da sua empresa, o que ajuda a alavancar sua própria carreira".

Gonçalves (2017) afirma que, por seu caráter educacional, visto que envolve atividades de aprendizagem, o treinamento integra os participantes, promove a socialização entre os colaboradores da empresa, bem como a melhoria das relações interpessoais. Freschi et al. (2006) observam, além disso, que o aumento da qualificação dos empregados leva à inovação, melhoria na qualidade de produtos e serviços e ampliação da fluência dos processos organizacionais, reduzindo falhas e perdas. A maior conscientização e comprometimento no trabalho gera um clima organizacional mais favorável, eleva a motivação individual e do grupo e melhora a imagem institucional da empresa.

Para Amaral (2014, p. 11):

O treinamento é um dos meios de desenvolver competências para que as pessoas se tornem mais produtivas, criativas e inovadoras, a fim de corresponderem aos objetivos da organização. Quando o treinamento é bem orientado e realizado, agrega valor. Quando direcionado, leva a valores e objetivos comuns, possibilitando o trabalho e a motivação de todos os membros da organização, gerando a sinergia necessária para 0 crescimento tanto individual como organizacional. 
Finalmente, na opinião de Chiavenato (2010, p. 294), o treinamento "enriquece o patrimônio humano das organizações", fomentando diretamente seu capital intelectual.

A par desses aspectos positivos, entretanto, os autores também observam barreiras e dificuldades para a adoção e prática do treinamento corporativo. Destacam-se aqui as principais.

A primeira e mais relevante diz respeito aos custos do treinamento, que são elevados. Em geral, a empresa precisa dispor de recursos financeiros consideráveis para os treinamentos em função da infraestrutura necessária para a realização de todas as suas fases, desde o planejamento até a execução e avaliação posterior.

No Brasil, em 2016, a média de investimento anual em treinamento e desenvolvimento (T\&D) por colaborador foi de $\mathrm{R} \$ 624,00$, representando um aumento de $24 \%$ sobre o investimento de 2015 , dado que evidencia a preocupação de algumas empresas em qualificar suas equipes em momentos desafiadores do mercado, com o objetivo de ter um time mais competitivo. Apesar disso, a média brasileira de investimentos anuais em T\&D dos profissionais se mantém bem abaixo da média norte-americana, que é de U\$1.229 por colaborador, conforme ilustra a Figura 2. (REVISTA T\&D, 2016).

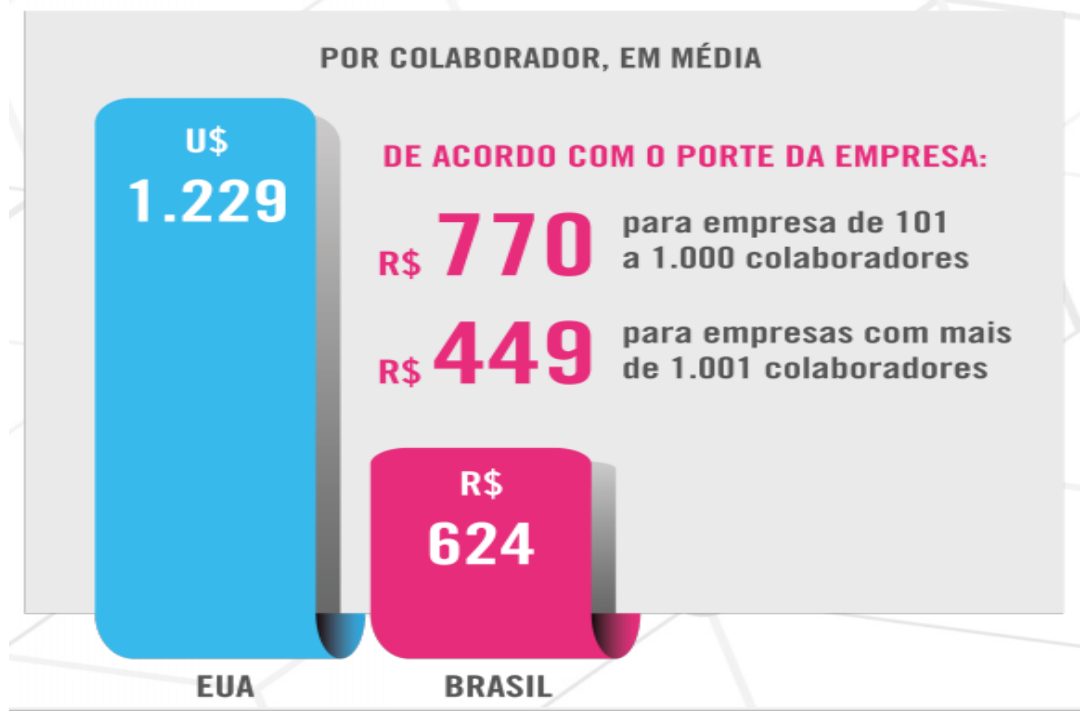

Figura 2: Investimento anual médio em T\&D: Estados Unidos e Brasil FONTE: REVISTA T\&D (2016, p. 3).

A questão dos recursos financeiros a serem empregados em treinamento é particularmente sensível quando a empresa possui uma visão tradicional da 
gestão dos recursos humanos. De acordo com Freschi et al. (2006), essa visão administrativa não reconhece a importância do treinamento.

Tal visão demonstra uma concepção limitada de homem e não enxerga a potencialidade humana e as necessidades além da remuneração e da rotina de trabalho. Não percebe 0 movimento das transformações e a necessidade constante de novos conhecimentos para acompanhá-las, além de não explorar as capacidades humanas a serem desenvolvidas para o benefício pessoal, organizacional e social. (FRESCHI et al., 2006, p. 2-3).

Por isso, muitas empresas ainda encaram o treinamento como algo custoso em tempo e dinheiro, preferindo contratar colaboradores que já possuem as habilidades desejadas. Ocorre que a contratação constante de novos profissionais gera um custo muito mais alto do que o dos treinamentos, sendo que, muitas vezes, o grau de especialização requisitado é tão elevado que a organização tem dificuldades em encontrar pessoas totalmente habilitadas para a atuação profissional esperada. (FRESCHI et al., 2006).

Para Milkovich e Boudreau (2006), o corte de programas de treinamento visando uma economia de curto prazo pode causar perda de produtividade e lucratividade no longo prazo, situação presente em muitas empresas, que não enxergam no treinamento uma forma de aumentar a produtividade e reduzir custos. É preciso considerar os benefícios do treinamento e, nesse contexto, entender que ele é investimento, e não custo ou despesa. Assim, programas de treinamento contínuos acabam sendo a melhor alternativa para diminuir os custos e garantir o melhor desempenho profissional. (FRESCHI et al., 2006). De acordo com Amaral (2014, p. 19):

\begin{abstract}
Investir em treinamento e desenvolvimento é uma das formas que as instituições encontram para trabalhar suas equipes de maneira a capacitá-las e, consequentemente, garantir o seu sucesso. O diferencial das organizações de sucesso é exatamente a capacidade de elas fazerem no presente o que tantas outras deixam para depois: capacitar seu capital intelectual em novas competências, ampliando visões e formando cidadãos da era do conhecimento.
\end{abstract}

Atualmente, investir em programas de aprimoramento e capacitação profissional é condição essencial para que a organização possa atuar de forma competitiva, garantindo e expandindo seu espaço de atuação, mas também, contribuindo bastante para o desenvolvimento das pessoas e da sociedade onde se insere. (FRESCHI et al., 2006). 
Outro ponto considerado barreira/dificuldade dos treinamentos é mencionado por Carvalho (1999). Segundo este autor, na grande maioria dos casos, o treinamento executado não tem qualquer relação com os planos estratégicos da organização, seja porque as pessoas que decidem não conseguem fazer a ligação entre ambos ou porque o responsável pelo treinamento não conhece os planos estratégicos da empresa. A principal consequência disso é que os planos de treinamento "acabam seguindo a inércia dos diagnósticos de deficiências individuais", raramente existindo "um acompanhamento mais sistemático e objetivo do desempenho do indivíduo e das circunstâncias que o cercam". (CARVALHO, 1999, p. 132).

A realização bem-sucedida de treinamentos também enfrenta mais uma barreira ou dificuldade, de interesse particular para a presente pesquisa: a própria concepção de treinamento adotada pela empresa, que pode ou não levar em consideração o indivíduo em si, seus objetivos e expectativas. Segundo Carvalho (1999), é frequente a existência de organizações em que:

\footnotetext{
O homem a ser treinado não é levado em consideração, a não ser para verificar de alguma maneira sua capacidade de se adaptar ao que é demandado. Ele não é levado em conta nem com relação aos seus próprios objetivos pessoais nem com relação à sua totalidade como ser humano. (CARVALHO, 1999, p. 132-134).
}

Conforme Freschi et al. (2006, p. 2), infelizmente muitos programas de treinamento visam somente preparar o trabalhador para produzir mais e melhor, "desconsiderando esta prática como um meio de transformação e desenvolvimento dos indivíduos que dela participam". 


\section{Métodos e procedimentos de coleta e de análise de dados do estudo}

Este capítulo se dedica à apresentação das diferentes etapas percorridas e procedimentos empregados para a realização desta parte da pesquisa. Informa o método utilizado, os procedimentos e instrumentos de coleta de dados, a forma como os dados coletados foram analisados e as limitações do estudo.

\subsection{Método de pesquisa utilizado}

A pesquisa se classifica como exploratória e descritiva. Segundo Gil (2009), explicação e descrição se aproximam, promovendo a compreensão de um dado objeto de estudo. Trata-se de modalidade "[...] que habitualmente realizam os pesquisadores sociais preocupados com a atuação prática”. (GIL, 2009, p. 42).

Tendo isso em vista, utilizou-se o estudo de caso como método de pesquisa, que é definido por Yin (2010) como uma investigação empírica que investiga um fenômeno contemporâneo em profundidade em seu contexto real. Yin (2010, p. 24) afirma que a estratégia do estudo de caso busca responder indagações do tipo 'como' e 'por que' e que este método "permite que os investigadores retenham características holísticas e significativas dos eventos da vida real", dentre outros, processos organizacionais e administrativos.

Desenvolveu-se aqui um estudo de caso único da Empresa $X$, com foco na percepção da empresa e de alguns de seus empregados sobre os treinamentos que a entidade realiza.

\subsection{Procedimento e instrumento de coleta de dados}

Diante do método utilizado, o procedimento empregado foi o levantamento primário de dados, realizado por meio de entrevista, técnica em que o pesquisador formula perguntas ao entrevistado com o objetivo de obter dados que interessam à investigação. (GIL, 2008).

Neste estudo, utilizou-se a entrevista estruturada, em que o pesquisador seguiu um roteiro de perguntas pré-fixadas, elaboradas a partir dos temas 
tratados na revisão de literatura. O Anexo A apresenta o roteiro de dez questões da entrevista realizada com quatro empregados ligados aos treinamentos realizados pela Empresa $X$ e o Anexo $B$ o roteiro da entrevista realizada com quatro empregados da empresa (de outros setores), com o mesmo número de questões. Portanto, a amostra é formada por oito pessoas, que foram selecionadas segundo a sua representatividade em relação aos objetivos da pesquisa.

Os componentes da amostra foram informados sobre a pesquisa e seus objetivos. Concordaram em participar mediante anonimato e o compromisso do pesquisador quanto à confidencialidade, fato que, acredita-se, contribuiu efetivamente para a veracidade das respostas - foram relevados apenas o gênero, as idades, os cargos que ocupam, o tempo de empresa, tempo lidando com treinamentos (para os responsáveis entrevistados), número de treinamentos recebidos (para os colaboradores entrevistados).

\subsection{Análise dos dados coletados}

Estudos exploratórios e descritivos, dentre eles os estudos de caso, prestam-se a investigações de natureza qualitativa. (YIN, 2010). Atendendo à classificação da pesquisa, bem como ao método utilizado e ao tamanho da amostra, os dados coletados receberam tratamento e análise qualitativos, permitindo ao pesquisador observar características do fenômeno em estudo, bem como interpretá-las em profundidade, o que não é possível nas pesquisas quantitativas, que são centradas em dados mensuráveis. A abordagem qualitativa na análise dos dados coletados viabiliza a compreensão e a interpretação das relações entre a realidade e o objeto de estudo. (VERGARA, 2010). Este processo de análise foi realizado com base nos assuntos tratados na revisão de literatura.

\subsection{Limitações do estudo}

A primeira limitação da pesquisa diz respeito à amostra, composta por oito pessoas, que pode ser considerada pequena para análises de natureza exploratória e descritiva. No entanto, acredita-se que essa limitação é compensada pela representatividade dos participantes frente aos objetivos da pesquisa, sobretudo tendo em vista que um comparativo entre as respostas de um e outro grupo entrevistado foi realizado. Outra limitação refere-se ao fato de 
apenas uma unidade de análise e interesse (a Empresa $\mathrm{X}$ ) ser investigada, muito embora o emprego do estudo de caso único seja válido para testar teorias. (YIN, 2010).

Isso implica a compreensão dos resultados do estudo dentro desses limites, não podendo ser generalizados a outros contextos e/ou unidades similares de investigação. Aliás, conforme Yin (2010), uma das limitações da estratégia dos estudos de caso é que eles fornecem pouca base para generalizações. 


\section{Apresentação e análise dos resultados}

Este capítulo está organizado em três seções. A primeira faz uma breve apresentação da Empresa $X$, objeto do estudo, em aspectos gerais. A segunda seção apresenta os dados coletados nas entrevistas realizadas com os empregados ligados aos treinamentos, bem como a análise desses dados. $\mathrm{Da}$ mesma forma, a terceira apresenta os dados coletados com os empregados que recebem treinamentos, bem como a análise desses dados.

\subsection{A Empresa $X$}

A Empresa $X$ é uma corporação transnacional de grande porte que atua no segmento de extração e produção (E\&P) de petróleo e gás. Fundada em 1973 na Noruega, nos últimos 15 anos, cresceu dez vezes em ativos, criou quatro empresas de capital aberto, fundando inúmeras joint ventures (parcerias empresariais). Atualmente, possui 175 plataformas flutuantes de produção, armazenamento e transferência espalhadas por 15 países (mais conhecidas como Floating Production, Storage and Offload Unit - FPSO, muito utilizadas na indústria de petróleo e gás offshore), 25 escritórios e cerca de 6.700 empregados. $^{3}$

No Brasil, as unidades e escritórios da Empresa X encontram-se no Rio de Janeiro, em Macaé e em Aracaju (SE). Atualmente, a empresa possui 83 empregados offshore (trabalhadores que embarcam) e 22 empregados onshore (de terra), entre gerentes, analistas, assistentes, almoxarifes e estagiários, todos responsáveis pela parte administrativa da corporação.

Em terra, a empresa possui também um gerente de manutenção e um coordenador de segurança do trabalho, que supervisionam as atividades de bordo. Cerca de $85 \%$ do conjunto de colaboradores responsáveis pela gestão e operação das unidades brasileiras é composto por profissionais de vários estados.

${ }^{3}$ As reservas offshore são localizadas em águas marinhas (rasas ou profundas) e atualmente correspondem à grande maioria das bacias mundiais com probabilidade de descoberta de petróleo. No Brasil, correspondem à quase totalidade das reservas nacionais, principalmente após a descoberta da camada Pré-sal. 
No estado de Sergipe, a Empresa $\mathrm{X}$ opera em águas profundas desde 2007, embora tenha passado a administrar totalmente sua plataforma na localidade em 2012. No início das operações desta unidade, a empresa utilizou seu primeiro FPSO cilíndrico. Esta plataforma foi a primeira a extrair óleo em águas profundas de um campo localizado no Nordeste. Na região, a empresa não possui concorrentes.

O organograma da unidade de Sergipe é formado basicamente por três grandes áreas: manutenção, produção e marinha. A área de marinha possui dois supervisores brasileiros enquanto a área de manutenção e produção possuem três supervisores estrangeiros. O regime de embarque é de $21 \times 42$ dias para os supervisores e 14x14 dias para o restante da tripulação. Os responsáveis pela unidade são chamados Offshore Installation Managers (OIM's), que fazem parte do topo da administração, três estrangeiros com regime de embarque $21 \times 42$ dias.

Desde 0 início de suas operações, a Empresa $X$ adotou o sistema de gestão integrada como ferramenta para melhor gerir a qualidade dos seus processos e serviços, os impactos ambientais e a saúde e segurança de seus colaborados. Pode-se dizer que na unidade de Sergipe a empresa possui um dos programas mais completos e eficientes de gestão de Qualidade, Segurança, Meio Ambiente e Saúde (QSMS), tendo em vista que em seis anos de trabalho não houve qualquer acidente com afastamentos. Esse é considerado um indicador relevante, principalmente por tratar-se de um ramo de atividade com risco 4 (maior indicador na escala de riscos).

A Empresa $X$ prioriza a boa manutenção de suas instalações, tendo em vista a influência direta que isto proporciona à sua produção. Orientando-se por padrões de sustentabilidade, busca hoje maior destaque em um mercado competitivo como o brasileiro. Dentro desse contexto, procura imprimir excelência em sua gestão visando novos acionistas, permanência dos existentes e aumento de seu lucro líquido (maximizando o retorno sobre o capital investido) por meio do fornecimento de soluções tecnológicas e comerciais inovadoras em novos e emergentes segmentos de mercado para criar valor aos acionistas.

A missão da Empresa $X$ é levar energia para o mundo, imprimindo o seu espírito 24 horas por dia, sete dias por semana. Sua visão é tornar-se uma organização conhecida mundialmente pela alta tecnologia e baixo custo de operação no segmento offshore. Seus valores são: segurança e sustentabilidade, paixão, integridade, confiabilidade, inovação e trabalho em equipe. 


\subsection{Respostas dos responsáveis pelos treinamentos e análise}

Apresentam-se os dados gerais dos empregados ligados aos treinamentos da Empresa $X$ que participaram do estudo, cuja média de idade é 28,5 anos. Eles foram nomeados aleatoriamente como Responsável $A$; Responsável $B$; Responsável C; e Responsável D, conforme Tabela 4.

Tabela 4: Dados gerais dos responsáveis pelos treinamentos

\begin{tabular}{|l|l|}
\cline { 2 - 3 } \multicolumn{1}{c|}{} & \multicolumn{1}{c|}{ DADOS GERAIS } \\
\hline Responsável A & $\begin{array}{l}\text { Mulher, 22 anos, ocupa o cargo de Estagiária de Treinamento. } \\
\text { Está na Empresa X há 1 ano e três meses e lida com } \\
\text { treinamentos há 1 ano e três meses }\end{array}$ \\
\hline Responsável B & $\begin{array}{l}\text { Mulher, 25 anos, ocupa o cargo de Analista de Treinamento. } \\
\text { Está na Empresa X há três anos e oito meses e lida com } \\
\text { treinamentos há cinco anos e oito meses }\end{array}$ \\
\hline Responsável C & $\begin{array}{l}\text { Homem, 42 anos, ocupa o cargo de Gerente de Treinamento. } \\
\text { Está na Empresa X há oito anos e três meses e é responsável } \\
\text { por treinamentos há oito anos e três meses }\end{array}$ \\
\hline Responsável D & $\begin{array}{l}\text { Mulher, 25 anos, ocupa o cargo de Analista de Treinamento. } \\
\text { Está na Empresa } X \text { há quatro anos, sendo responsável por } \\
\text { treinamentos há três anos }\end{array}$ \\
\hline
\end{tabular}

FONTE: Elaborado pelo autor.

Foi indagado o que é treinamento para estes participantes. Três alternativas foram apresentadas, não se limitando a escolha de apenas uma. $O$ Responsável A assinalou que treinamento é uma forma de aprimorar as habilidades dos recursos humanos para que a empresa ganhe em produtividade. Os outros três responsáveis assinalaram duas alternativas: uma forma de aprimorar as habilidades dos recursos humanos para que a empresa ganhe em produtividade e o processo que faz parte do desenvolvimento e aprendizagem contínua das pessoas, tornando-se uma via para que as empresas alcancem suas metas e seus objetivos.

A opção uma forma de aprimorar as habilidades dos recursos humanos para que a empresa ganhe em produtividade, assinalada pelos quatro participantes do grupo, é ultrapassada por corresponder à segunda fase evolutiva do conceito de treinamento, na qual o ser humano era visto como um recurso adicional. (GONÇALVES, 2017). Já o treinamento visto como um processo que faz parte do desenvolvimento e aprendizagem contínua das pessoas, tornando-se uma via para que as empresas alcancem suas metas e seus objetivos, opção assinalada por três participantes, corresponderia hoje ao entendimento mais correto, pois se relaciona à atual e presente fase do conceito de treinamento, tendo em vista a visão do ser humano em sua complexidade e 
capacidade de expressar-se de maneira crítica e reflexiva. (GONÇALVES, 2017). Vê-se, portanto, que o grupo ainda não possui uma concepção cristalizada de treinamento corporativo. Mas, pelo ninguém afirmou que ele é uma espécie de adestramento de recursos humanos para que estes sejam produtivos no desempenho de tarefas específicas do cargo. Conforme Gonçalves (2017), o treinamento não pode ser encarado como um processo mecanicista e adestrador.

Foi solicitado aos responsáveis que apontassem vantagens/benefícios dos treinamentos. Alguns desses itens foram mencionados por mais de um participante. A Figura 3 mostra as vantagens/benefícios relatadas e o número de vezes que foram citadas.

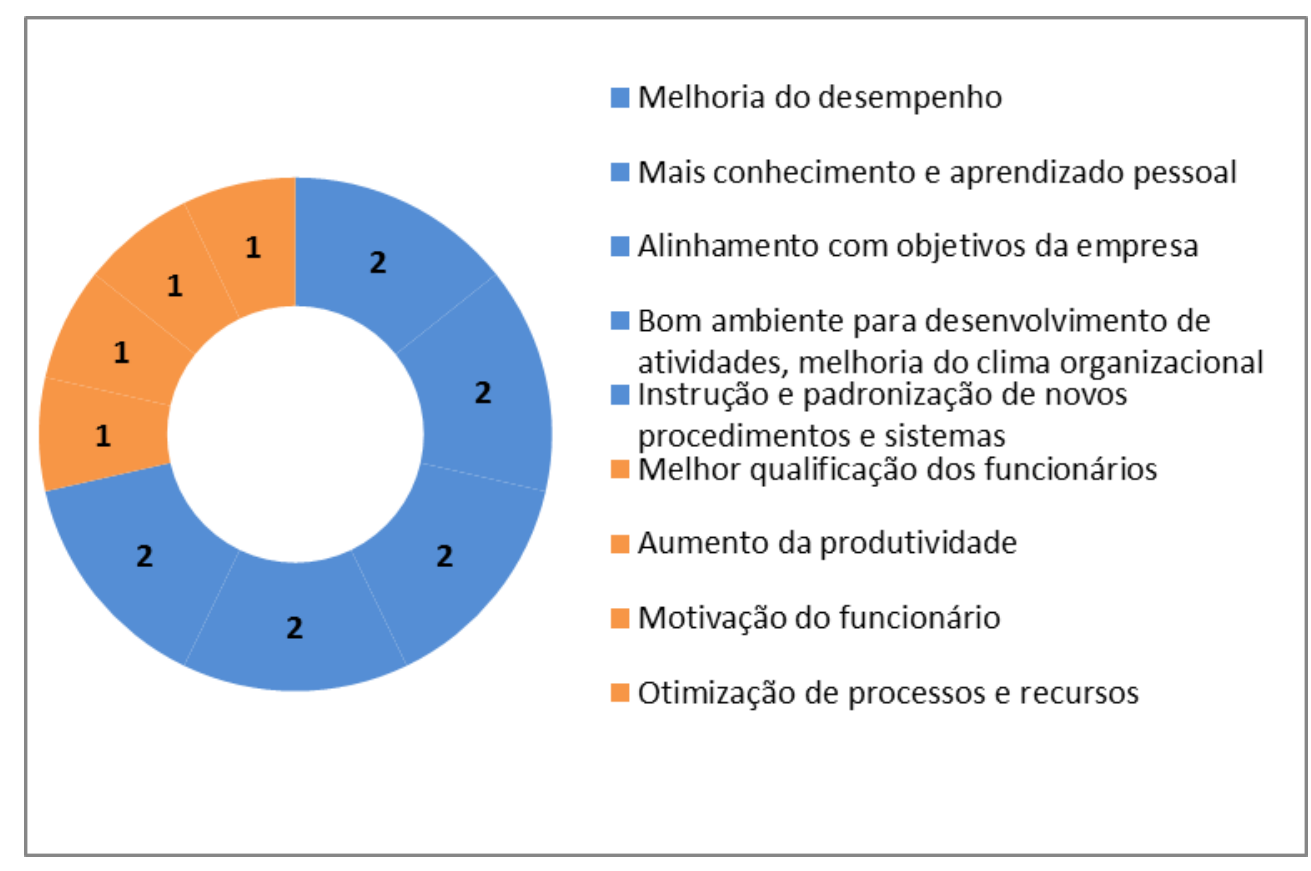

Figura 3: Gráfico das vantagens/benefícios dos treinamentos FONTE: Elaborado pelo autor.

A maioria das vantagens/benefícios citadas coincide com a visão da literatura a respeito. Conhecimento e aprendizado são apontados por Freschi et al. (2006), Gonçalves (2017) e Boog (2001) como benefícios dos treinamentos. O efeito do alinhamento com os objetivos da empresa é mencionado por Amaral (2014) e Chiavenato (2004, 2010). Freschi et al. (2006) relacionam os treinamentos à maior conscientização e comprometimento no trabalho, e estes, por sua vez, geram melhor ambiente e um clima organizacional mais favorável, assim como a ampliação da fluência dos processos organizacionais. Os mesmos autores ressaltam o aumento da qualificação dos empregados. A motivação dos 
empregados e do grupo é destacada por Amaral (2014) enquanto o aumento da produtividade por Chiavenato (2004) e Boog (2001).

Também foi solicitado ao grupo de responsáveis que apontasse as barreiras/dificuldades dos treinamentos. E, assim como na questão anterior, houve coincidência entre aspectos citados. A Figura 4 mostra barreiras/dificuldades apontadas e o número de vezes que foram citadas.

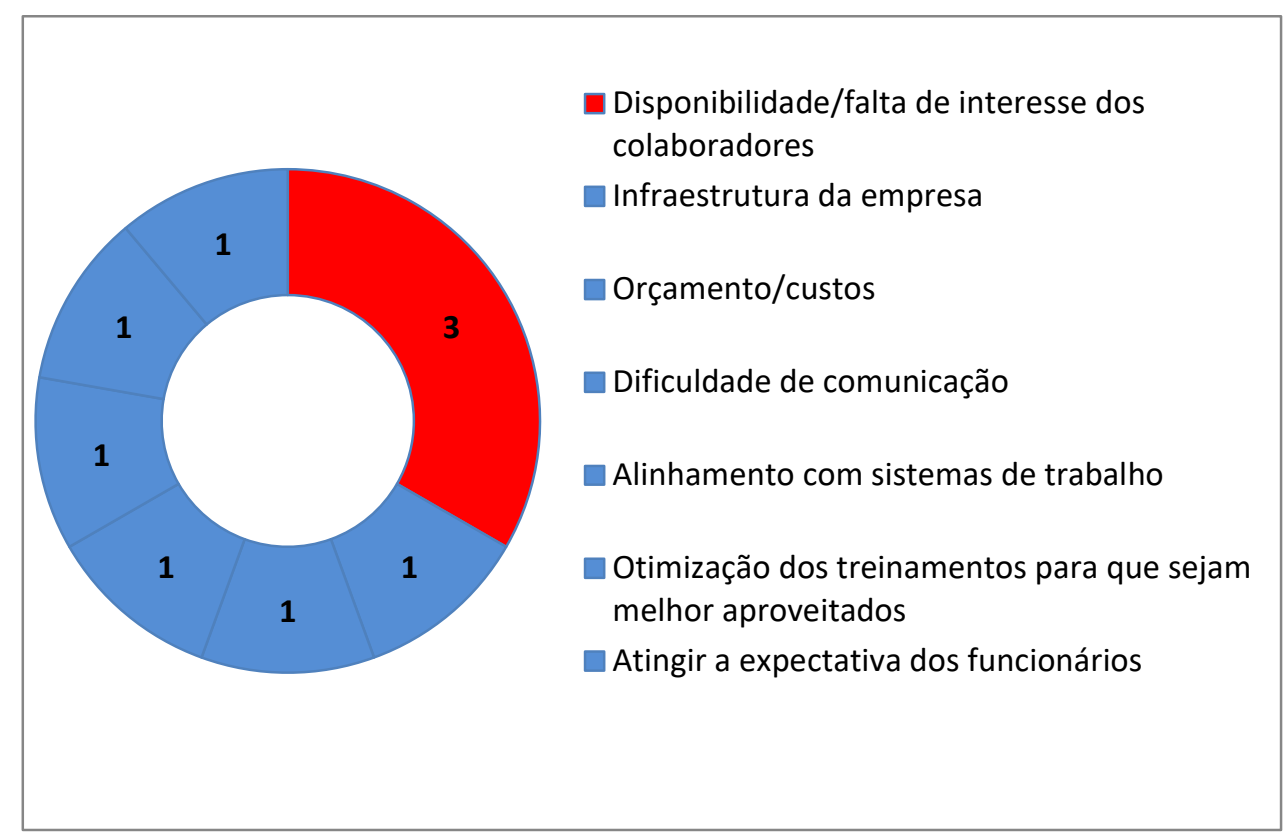

Figura 4: Gráfico das barreiras/dificuldades dos treinamentos FONTE: Elaborado pelo autor.

A barreira/dificuldade citada em maior número de vezes pelos participantes deste grupo foi disponibilidade/falta de interesse dos colaboradores. Alguns deles complementaram esse item, mencionando suas percepções a respeito: que os empregados não veem relevância nos treinamentos, que não aproveitam o tempo direcionado ao treinamento, que treinamentos obrigatórios parecem não agregar valor e que as pessoas não gostam de ficar lendo sobre conceitos. Esses aspectos podem parecer meramente subjetividades dos colaboradores, porém essa indisponibilidade/falta de interesse pode relacionar-se ao tipo de treinamento que vem sendo majoritariamente empregado na Empresa $\mathrm{X}$, bem como à técnica utilizada, que, se, inadequados podem produzir efeitos adversos.

Quanto ao tipo de treinamento, o treinamento comportamental talvez pudesse contribuir para superar ou minimizar esta barreira/dificuldade na Empresa $X$, uma vez que sua finalidade é estruturar adequadamente a melhoria das relações humanas, da comunicação e das habilidades intra e interpessoal no ambiente de trabalho. (GONÇALVES, 2017). Segundo Costa e Santana 
(2013), no treinamento comportamental, um dos temas focados é a comunicação, outra barreira/dificuldade mencionada. A aplicação desse tipo de treinamento poderia, inclusive, otimizar os treinamentos para que eles fossem melhor aproveitados (outra barreira/dificuldade mencionada). Já em termos técnicos, a utilização de recursos tecnológicos talvez promovesse maior motivação dos empregados da Empresa $X$ em relação a esta ação.

A dificuldade/barreira relativa à infraestrutura remete à possibilidade de a Empresa $X$ não possuir recursos (os mais diversos) suficientes para realizar treinamentos como eles devem ser idealmente implementados, isto é, levando em conta as quatro fases sugeridas por Boog (2001), diagnóstico, elaboração, execução e avaliação. Pode-se dizer que esta barreira/dificuldade tem ligação direta com outra mencionada pelos participantes, a questão do orçamento/custos. De fato, de acordo com a literatura, a primeira e mais relevante dificuldade na implementação dos treinamentos diz respeito aos custos, que são elevados em qualquer parte do mundo, inclusive no Brasil. (REVISTA T\&D, 2016).

Quanto à dificuldade de os treinamentos alcançarem as expectativas dos empregados, variável que norteia a presente pesquisa, é fato que muitas organizações desconsideram tais expectativas, seja em âmbito profissional ou pessoal, muitas vezes priorizando a capacidade de adaptação do colaborador ao que é demandado e ignorando a visão dos treinamentos como um meio de transformação e desenvolvimento de pessoas. (CARVALHO, 1999). Talvez isso esteja ocorrendo na empresa em estudo.

$\mathrm{Na}$ questão número 4, cinco afirmações sobre a Empresa $X$ foram propostas, solicitando-se ao participante que assinalasse $V$ para verdadeiro e $F$ para falso. A Tabela 5 mostra as afirmativas e o número de vezes que cada uma recebeu $\mathrm{V}$ e F.

Tabela 5: Verdadeiro ou Falso sobre a Empresa X

\begin{tabular}{|l|l|l|}
\cline { 2 - 3 } \multicolumn{1}{l|}{$\begin{array}{l}\text { A Empresa X valoriza o capital humano e seu capital intelectual, pois } \\
\text { requer aprendizado constante de seus colaboradores }\end{array}$} & 4 & - \\
\hline $\begin{array}{l}\text { A Empresa X não tem cultura organizacional voltada para a expansão do } \\
\text { conhecimento de seus colaboradores }\end{array}$ & 1 & 3 \\
\hline A Empresa X ainda possui uma visão mecanicista do setor de RH & 1 & 3 \\
\hline $\begin{array}{l}\text { O setor de RH da Empresa X trabalha com o conceito de gestão de } \\
\text { pessoas em todos os seus aspectos }\end{array}$ & 3 & 1 \\
\hline O setor de RH não é estratégico na empresa & - & 4 \\
\hline
\end{tabular}

FONTE: Elaborado pelo autor. 
Nota-se pelas respostas que a maioria dos componentes desse grupo acredita que a Empresa $X$ valoriza o capital humano e seu capital intelectual e que possui cultura organizacional voltada para o desenvolvimento das pessoas, afirmações que implicam a adoção do conceito de gestão de pessoas em relação à administração de $\mathrm{RH}$. A maioria do grupo também acredita que a empresa considera o $\mathrm{RH}$ um setor estratégico e que aplica as melhores práticas em termos de treinamento.

$\mathrm{Na}$ sequência, foi solicitado a esses participantes que apontassem algumas razões para a Empresa $X$ realizar treinamentos. Algumas das razões apresentadas puderam ser agrupadas por se referirem aos mesmos temas ou a temas afins, como indicado na Tabela 6 , que mostra também o número de vezes que cada uma foi mencionada.

Tabela 6: Razões para a Empresa $X$ realizar treinamentos

\begin{tabular}{|l|l|}
\hline Cumprimento de normas regulatórias/criação de códigos de conduta & 4 \\
\hline $\begin{array}{l}\text { Criação de cultura de treinamentos, de controles internos contra } \\
\text { riscos/segurança }\end{array}$ & 3 \\
\hline Alinhamento aos objetivos da empresa & 2 \\
\hline Padronização de atividades/conformidade nas operações & 2 \\
\hline Uso de ferramentas e sistemas adequados & 1 \\
\hline Melhoria nos conhecimentos e desempenho dos colaboradores & 1 \\
\hline Criação de bom ambiente para melhor desenvolvimento de atividades & 1 \\
\hline
\end{tabular}

FONTE: Elaborado pelo autor.

Dentre as razões apresentadas, merecem destaque: cumprimento de normas regulatórias/criação de códigos de conduta; criação de cultura de treinamentos, de controles internos contra riscos/segurança; padronização de atividades/conformidade nas operações; e uso de ferramentas e sistemas adequados, o que mostra preocupação prioritária com os impactos das atividades da Empresa $X$ sobre a sociedade e meio ambiente.

A questão número 6 indagou que tipos de treinamento são mais frequentemente empregados na Empresa $X$, dentre quatro mencionados: treinamento de integração, técnico-operacional, gerencial e comportamental. Dois participantes assinalaram os quatro tipos. Um assinalou treinamento técnico-operacional e treinamento comportamental e outro treinamento técnicooperacional, treinamento gerencial e treinamento comportamental. Para efeito de análise de dados, é prudente não considerar as respostas dos dois participantes que assinalaram todos os tipos de treinamento, até porque foi pedido que apontassem os treinamentos mais usados na empresa. Levando em conta as respostas dos outros dois participantes, conclui-se, por maioria, que a Empresa 
$X$ realiza com mais frequência $o$ treinamento técnico-operacional e 0 comportamental.

Os autores não manifestam preferência por algum tipo de treinamento, afirmam apenas que a empresa pode priorizar determinados tipos conforme seus objetivos. (GONÇALVES, 2017; CHIAVENATO, 2010). No caso da Empresa X, devido ao ramo de atuação, a realização de treinamento técnico-operacional, por exemplo, até se justifica, uma vez que ele visa capacitar o colaborador com informações técnicas sobre funções e responsabilidades do cargo e desenvolvimento de habilidades operacionais relevantes para o desempenho de tarefas específicas. (MILKOVICH e BOUDREAU, 2006; GONÇALVES, 2017).

Dentre 15 alternativas, foi pedido que os membros desse grupo apontassem as técnicas de treinamento mais comumente empregadas na Empresa X. As opções jogos cooperativos, dramatizações, estudos de caso e laboratório virtual, livro eletrônico, e-mail, chats, sites, não foram assinaladas. As técnicas leituras e estágios foram assinaladas uma vez cada; conferências e seminários, dinâmicas e discussões em grupo e videoconferências receberam duas menções cada uma. Com três menções, aulas expositivas e workshops. Já as técnicas palestras, cursos presenciais, instrução on-line e treinamento a distância (e-learning) foram as que receberam menções de todos os participantes deste grupo, o que permite concluir que são elas as mais frequentemente utilizadas pela empresa em seus treinamentos.

A pergunta 8 indagou qual a periodicidade dos treinamentos realizados pela Empresa $X$ e quantos empregados eles abrangem aproximadamente. $A$ Tabela 7 mostra as respostas dos responsáveis pelos treinamentos na empresa.

Tabela 7: Periodicidade dos treinamentos e empregados que abrangem

\begin{tabular}{|l|l|}
\hline Responsável A & $\begin{array}{l}\text { Não existe periodicidade, os treinamentos são realizados } \\
\text { conforme a necessidade de atualização dos empregados. Não } \\
\text { abrangem um número certo, mas englobam cerca de 15 } \\
\text { empregados }\end{array}$ \\
\hline Responsável B & $\begin{array}{l}\text { Periodicidade mensal. O número de empregados depende da } \\
\text { área da empresa e da necessidade de treinamento }\end{array}$ \\
\hline Responsável C & $\begin{array}{l}\text { Periodicidade mensal. O número de empregados depende da } \\
\text { necessidade de treinamento e da atualização do treinamento }\end{array}$ \\
\hline Responsável D & $\begin{array}{l}\text { A periodicidade varia conforme a demanda, mas a cada novo } \\
\text { empregado corresponde um roteiro de treinamentos a ser } \\
\text { seguido. Não existe um número certo. O número varia à medida } \\
\text { que eles precisam de atualização }\end{array}$ \\
\hline
\end{tabular}

FONTE: Elaborado pelo autor.

Como é possível observar na Tabela acima, não existe unanimidade entre os participantes quanto à periodicidade dos treinamentos: dois responderam que 
não existe periodicidade e dois disseram que os treinamentos ocorrem mensalmente. Já quanto ao número aproximado de empregados que cada treinamento abrange, esta sim foi uma resposta unânime: não há um número fechado de empregados a cada treinamento.

Questionou-se a seguir se os resultados dos treinamentos têm sido positivos para a Empresa $X$ e por quê. Todos afirmaram que sim, embora nem sempre pelas mesmas razões. Dois deles disseram que os treinamentos são positivos porque em geral atingem os objetivos propostos. Um disse que sim argumentando que na maioria das vezes as pessoas são treinadas dentro do prazo estabelecido e que o número de colaboradores que estão com treinamentos pendentes é baixo. O último afirmou que sim porque a empresa treina seus empregados dentro dos procedimentos e políticas que ela estabelece, sendo que os treinamentos técnicos aperfeiçoam o trabalho do colaborador.

Pode-se concluir que este grupo está firmemente convencido dos resultados positivos dos treinamentos para a empresa em questão. Destaca-se, dentre as justificativas, aquela que faz referência aos prazos de treinamento e ao baixo número de pessoas com treinamento pendente. De fato, o treinamento corporativo, diante de seu caráter educacional, é visto pela literatura como um processo sistemático, cíclico e organizado. (BOOG, 2001; MILKOVICH e BOUDREAU, 2006; CHIAVENATO, 2008). É a continuidade dos treinamentos que os insere nas políticas de educação continuada das empresas. (FRESCHI et al., 2006).

Finalmente, foi indagado ao participante deste grupo se ele tem críticas e/ou sugestões no sentido de melhorar as atividades de treinamento da Empresa $X$ e, em caso positivo, quais. Três afirmaram que não e um que sim. $O$ Responsável $A$ afirmou não ter críticas ou sugestões, pois considera que os treinamentos têm sido positivos também para os empregados, uma vez que eles podem ter uma visão mais ampla da empresa, aprendizado e oportunidades internas. O Responsável B afirmou que não. O Responsável C também disse que não, observando que recentemente houve reformulação no monitoramento dos treinamentos e na comunicação com os empregados: a empresa criou uma plataforma na qual os treinamentos são direcionados às pessoas que precisam fazer atualizações ou mesmo novos treinamentos, o que produz resultados satisfatórios. O Responsável $D$ considerou que os resultados dos treinamentos da Empresa $X$ poderiam ser mais positivos caso todos os empregados tivessem acesso aos treinamentos técnicos, evitando os mesmos erros do passado. 
Para a maioria do grupo, portanto, não há críticas e/ou sugestões a fazer no que tange à melhoria ou aperfeiçoamento dos treinamentos que vêm sendo aplicados na Empresa X.

\subsection{Respostas dos empregados e análise}

Os dados gerais dos empregados, cuja média de idade é 26,5 anos, são observados na Tabela 8.

Tabela 8: Dados gerais dos empregados

\begin{tabular}{|l|l|}
\cline { 2 - 2 } \multicolumn{1}{c|}{} & \multicolumn{1}{c|}{ DADOS GERAIS } \\
\hline Colaborador A & $\begin{array}{l}\text { Homem, 24 anos, ocupa o cargo de Estagiário de Compras. Está } \\
\text { na Empresa X há um (01) ano e recebeu dois treinamentos }\end{array}$ \\
\hline Colaborador B & $\begin{array}{l}\text { Homem, 32 anos, ocupa o cargo de Analista de Compras. Está } \\
\text { na Empresa X há cinco anos e recebeu dez treinamentos }\end{array}$ \\
\hline Colaborador C & $\begin{array}{l}\text { Mulher, 25 anos, ocupa o cargo de Analista de Contas a Pagar e } \\
\text { Tesouraria. Está há cinco anos e oito meses na Empresa X e } \\
\text { recebeu três treinamentos }\end{array}$ \\
\hline Colaborador D & $\begin{array}{l}\text { Mulher, 25 anos, ocupa o cargo de Analista de Treinamento. } \\
\text { Está na Empresa X há três anos e não recebeu treinamentos }\end{array}$ \\
\hline
\end{tabular}

FONTE: Elaborado pelo autor.

Foi indagado se o colaborador acha importante a aplicação de treinamentos dentro das instalações da empresa. Os quatro participantes afirmaram que sim e apresentaram as razões, como foi solicitado. A Tabela abaixo mostra essas razões e o número de vezes que cada uma foi mencionada.

Tabela 9: Por que os treinamentos nas instalações da empresa são importantes

\begin{tabular}{|l|l|}
\hline Alinham habilidades de acordo com as exigências da empresa & 1 \\
\hline $\begin{array}{l}\text { Fornecem subsídios para melhor desempenho do trabalho (evitando erros do } \\
\text { dia a dia) }\end{array}$ & 2 \\
\hline $\begin{array}{l}\text { Cumprem de normas de compliance, como ocorre com os treinamentos } \\
\text { obrigatórios para áreas específicas }\end{array}$ & 1 \\
\hline Motivam o funcionário & 1 \\
\hline $\begin{array}{l}\text { Padronizam o modo de trabalho e procedimentos a serem adotados em } \\
\text { diversas situações }\end{array}$ & 1 \\
\hline Melhoram a qualificação dos empregados & 1 \\
\hline Atualizam quanto a novos procedimentos e sistemas & 1 \\
\hline
\end{tabular}

FONTE: Elaborado pelo autor.

Conforme se pode observar, o melhor desempenho no trabalho proporcionado pelo treinamento aplicado dentro das instalações da empresa foi a razão que teve maior número de menções, sendo apontada por dois colaboradores. 
Essa visão coincide com Carvalho (apud AMARAL, 2014), segundo o qual a principal finalidade do treinamento é proporcionar desempenho adequado ao trabalhador nas atividades que ele desenvolve. No entanto, não é compatível com a visão de outros autores. Boog (2001), por exemplo, considera treinamento o processo voltado para o desenvolvimento e promoção do conhecimento, habilidades e comportamento dos empregados. Chiavenato (2010) tem a mesma opinião, pois avalia que por meio do treinamento as pessoas aprendem conhecimentos e desenvolvem habilidades e competências. Já Gonçalves (2017) afirma que os treinamentos devem qualificar o indivíduo em termos de habilidades, conhecimentos e atitudes.

A segunda questão pediu que o colaborador assinalasse $V$ (verdadeiro) ou $F$ (falso) para seis afirmações sobre a Empresa X. A Tabela 10 mostra as afirmativas e o número de vezes que receberam $\mathrm{V}$ e $\mathrm{F}$.

Tabela 10: Verdadeiro ou Falso sobre a Empresa X

\begin{tabular}{|l|l|l|}
\cline { 2 - 3 } \multicolumn{1}{l|}{} & V Empresa X estimula o desenvolvimento profissional de seus & $F$ \\
empregados & 3 & 1 \\
\hline $\begin{array}{l}\text { A Empresa X não tem cultura organizacional voltada para a expansão do } \\
\text { conhecimento de seus colaboradores }\end{array}$ & 2 & 2 \\
\hline $\begin{array}{l}\text { A Empresa X desenvolve treinamentos para aumentar a produtividade da } \\
\text { organização }\end{array}$ & 2 & 2 \\
\hline Os empregados da Empresa X são vistos como recursos & 2 & 2 \\
\hline $\begin{array}{l}\text { Em geral, a Empresa X reconhece o potencial humano de seu quadro de } \\
\text { colaboradores }\end{array}$ & 2 & 2 \\
\hline Os empregados da Empresa X são vistos como parceiros & 4 & - \\
\hline
\end{tabular}

FONTE: Elaborado pelo autor.

Em quatro sentenças propostas - a Empresa $X$ não tem cultura organizacional voltada para a expansão do conhecimento de seus colaboradores; a Empresa $X$ desenvolve treinamentos para aumentar a produtividade da organização; os empregados da Empresa $X$ são vistos como recursos; em geral, a Empresa $X$ reconhece o potencial humano de seu quadro de empregados - houve uma clara divisão de opinião entre os colaboradores: em igual número, eles consideraram cada uma dessas sentenças como verdadeira e falsa, resultado que praticamente inviabiliza uma conclusão, ao menos baseada na opinião da maioria.

Por outro lado, esse empate entre verdadeiro e falso não apresenta coerência com o resultado encontrado para as proposições que receberam maior número de menções, a Empresa $X$ estimula o desenvolvimento profissional de seus empregados, que obteve três marcações como verdadeira e uma como 
falsa, e os empregados da Empresa $X$ são vistos como parceiros, que obteve quatro menções como verdadeira.

$\mathrm{Na}$ terceira questão, foi apresentada uma relação de 15 técnicas de treinamento e perguntado ao colaborador quais delas foram mais utilizadas com ele nos treinamentos recebidos na Empresa X. As técnicas jogos cooperativos, dramatizações e estudos de caso não foram assinaladas. Estágios; palestras; cursos presenciais; dinâmicas e discussões em grupo; e laboratório virtual, livro eletrônico, e-mail, chats, sites foram técnicas assinaladas uma vez cada. Já as técnicas workshops, conferências e seminários e videoconferências foram assinaladas duas vezes cada uma. As técnicas mais assinaladas pelos participantes foram leituras, aulas expositivas e treinamento a distância (elearning), cada qual com três menções, e instrução on-line, que foi mencionada pelos quatro colaboradores.

A literatura consultada (BOOG, 2001; PILLA, 2002; MILKOVICH e BOUDREAU, 2006) não se posiciona sobre quais seriam as melhores técnicas de treinamento. No entanto, diante das respostas dos colaboradores, deduz-se que os treinamentos com base na tecnologia têm sido mais frequentemente utilizados pela Empresa $\mathrm{X}$, vide o número de menções à instrução on-line.

A quarta questão indagou se os colaboradores se sentem envolvidos com os treinamentos que recebem da Empresa $X$. Solicitou-se que apontassem cinco razões que justificassem a sua escolha entre dez apresentadas.

Três empregados responderam que sim, se sentem envolvidos com os treinamentos realizados pela Empresa $X$. Porque tenho grande interesse em ser treinado pela empresa; porque os treinamentos da empresa são bem planejados e executados; porque me sinto motivado por ver que a empresa valoriza as pessoas; e porque as técnicas utilizadas são modernas foram razões que receberam uma menção cada. As razões que receberam duas e três menções podem ser vistas na Figura 5. 


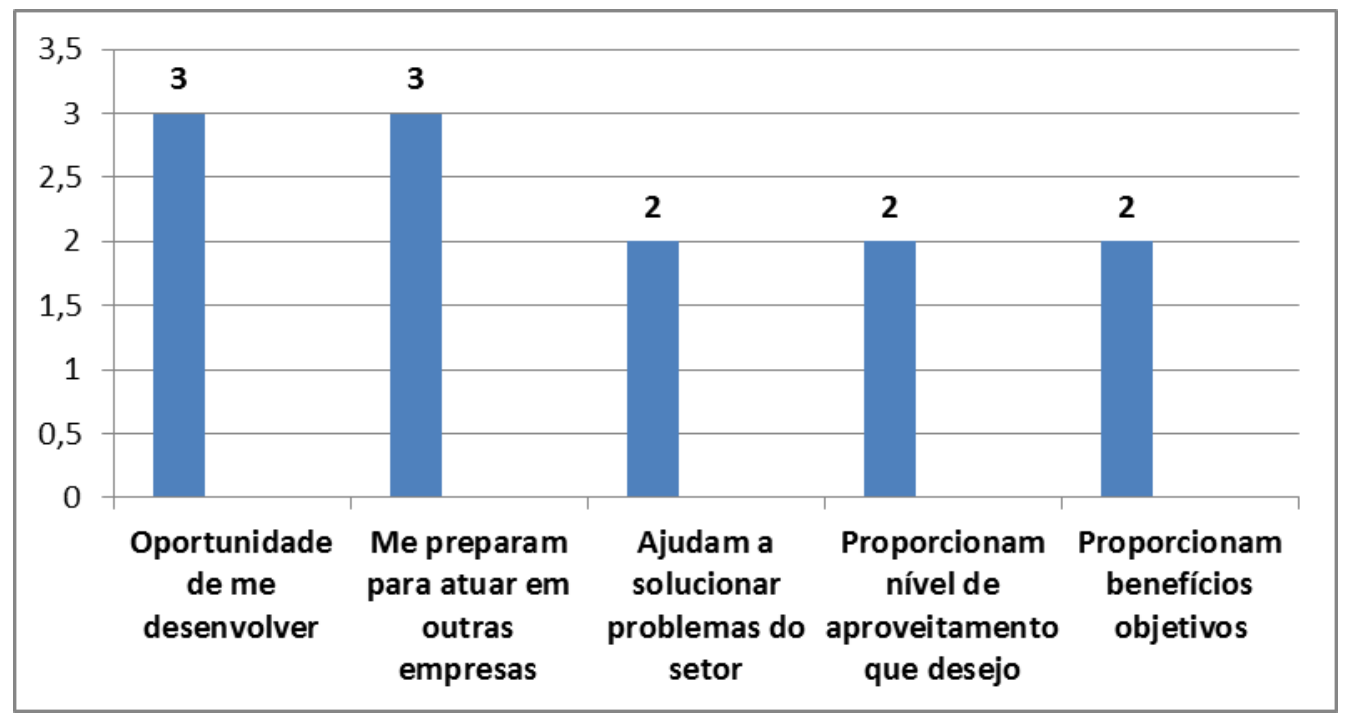

Figura 5: Gráfico das razões do envolvimento com os treinamentos da Empresa $X$ FONTE: Elaborado pelo autor.

Inicialmente, chama a atenção o fato de nenhum dos três empregados que disseram sentir-se envolvidos com os treinamentos da empresa ter assinalado a opção porque os treinamentos que a Empresa $X$ realiza são também orientados para satisfazer as minhas necessidades e expectativas pessoais, o que contraria alguns autores consultados - como Pilla (2002), Gonçalves (2017), Milkovich e Boudreau (2006), Carvalho (1999), Freschi et al. (2006) - segundo os quais é importante que as organizações levem em conta aspectos humanos dos empregados em suas estratégias de treinamento (tais como características, particularidades e objetivos pessoais) justamente para que suas expectativas sejam atendidas.

Outro resultado a ser destacado no mesmo sentido diz respeito às justificativas que obtiveram três menções cada uma - porque os treinamentos são uma oportunidade de me desenvolver e porque eles preparam para que eu atue em outras empresas, aumentando minhas chances profissionais -, pois ele que reforça a ideia de que os empregados efetivamente possuem expectativas profissionais e pessoais quando recebem treinamentos.

Um dos colaboradores afirmou que não se sente envolvido com os treinamentos que recebe da Empresa $X$. Suas justificativas foram: porque os treinamentos não acrescentam para a prática do dia a dia na empresa; porque, na verdade, a empresa treina pouco seus empregados; porque as técnicas utilizadas são muito antiquadas; porque os treinamentos não me proporcionam o nível de aproveitamento que desejo; e porque os treinamentos da Empresa $X$ não aumentam minhas chances de atuação profissional. Embora esse resultado 
represente a minoria, não deve ser desconsiderado, pois pode sinalizar que a empresa não veja no treinamento um meio de transformação e desenvolvimento de pessoas, como identificam Freschi et al. (2006) acerca de muitos programas de treinamento.

$\mathrm{Na}$ sequência, pergunta 5 , indagou-se ao colaborador se ele recebe um feedback da empresa sobre o seu desempenho/atuação após receber um treinamento. Três colaboradores responderam que não enquanto um disse que sim. Portanto, a maioria não tem um retorno sobre a sua performance após ter sido treinado. Esse não pode ser considerado um bom resultado, especialmente porque o feedback pode ser incluído na fase de avaliação do treinamento, mencionada por Boog (2001). O retorno é importante porque, para o empregado, o treinamento é uma experiência que permite mudanças comportamentais que repercutem positivamente na capacidade de desempenho e nas interações com colegas e supervisores. (CHIAVENATO, 2010).

A questão de número 6 quis saber como o colaborador encara o treinamento que recebe da Empresa X. Foram propostas 13 afirmações e solicitado que o colaborador assinalasse $V$ para verdadeiro e $F$ para falso. A Tabela 11 mostra a resposta dos empregados, detalhando o número de verdadeiro e falso que cada afirmação recebeu.

Tabela 11: Verdadeiro ou Falso para a percepção dos treinamentos da Empresa $X$

\begin{tabular}{|l|l|l|}
\cline { 2 - 3 } \multicolumn{1}{l|}{ Os treinamentos que recebi contribuíram para eu me adaptar ao trabalho } & 3 & 1 \\
\hline $\begin{array}{l}\text { Os treinamentos que recebi revelaram que a Empresa X não considera o } \\
\text { funcionário em seus objetivos e expectativas pessoais }\end{array}$ & 3 & 1 \\
\hline $\begin{array}{l}\text { Os treinamentos que recebi contribuíram para a mudança no meu } \\
\text { comportamento }\end{array}$ & - & 4 \\
\hline $\begin{array}{l}\text { Os treinamentos que recebi contribuíram para eu repensar meus padrões } \\
\text { de atuação }\end{array}$ & - & 4 \\
\hline $\begin{array}{l}\text { Os treinamentos que eu recebi visaram apenas me preparar para produzir } \\
\text { mais e melhor para a empresa }\end{array}$ & 4 & - \\
\hline $\begin{array}{l}\text { Os treinamentos que eu recebi foram uma grande oportunidade para eu } \\
\text { me autodesenvolver }\end{array}$ & 2 & 2 \\
\hline $\begin{array}{l}\text { Com os treinamentos, eu me sinto parte fundamental do sucesso da } \\
\text { empresa }\end{array}$ & 1 & 3 \\
\hline Os treinamentos que recebi não me desenvolveram ou me transformaram & 2 & 2 \\
\hline $\begin{array}{l}\text { Os treinamentos promoveram melhor socialização e integração com meus } \\
\text { colegas }\end{array}$ & 3 & 1 \\
\hline $\begin{array}{l}\text { Os treinamentos da empresa não consideraram minhas características e } \\
\text { particularidades pessoais }\end{array}$ & 1 & 4 \\
\hline Os treinamentos que recebi me qualificaram profissionalmente & 2 & 2 \\
\hline Os treinamentos da Empresa X não promoveram aprendizagem coletiva & 2 & 2 \\
\hline $\begin{array}{l}\text { Com os treinamentos, me senti mais produtivo, criativo e inovador no } \\
\text { trabalho }\end{array}$ & 1 & 3 \\
\hline
\end{tabular}

FONTE: Elaborado pelo autor. 
De acordo com a Tabela acima, quatro afirmações - os treinamentos que eu recebi foram uma grande oportunidade para eu me autodesenvolver; os treinamentos que recebi não me desenvolveram ou me transformaram; os treinamentos que recebi me qualificaram profissionalmente; e os treinamentos da Empresa $X$ não promoveram aprendizagem coletiva - receberam igual número de $\mathrm{V}$ e $\mathrm{F}$, ficando assim empatadas. Esse resultado demonstra uma clara divisão entre os empregados sobre temas importantes, principalmente quanto à percepção sobre o seu autodesenvolvimento e transformação, um dos aspectos mais destacados pela literatura na definição de treinamento. (CHIAVENATO, 2004, 2010; GONÇALVES, 2017; BOOG apud AMARAL, 2014).

O mesmo se pode concluir em relação ao resultado obtido da afirmação com os treinamentos me senti mais produtivo, criativo e inovador no trabalho, que recebeu três menções para falso e apenas uma para verdadeiro, resultado esse que parece guardar coerência direta ao obtido da afirmação com os treinamentos eu me sinto parte fundamental do sucesso da empresa, falsa para três empregados e verdadeira apenas para um. Ou seja, na medida em que a maioria não se sentiu mais produtivo, criativo e inovador no trabalho após receber treinamentos, a mesma maioria não se sente parte do sucesso da Empresa X, muito embora Amaral (2014) sugira uma relação entre o investimento no colaborador com o fato de ele sentir-se elemento fundamental para o sucesso da sua empresa.

Um colaborador assinalou $\mathrm{F}$ para a afirmação os treinamentos que recebi contribuíram para eu me adaptar ao trabalho enquanto três assinalaram $\mathrm{V}, \mathrm{o}$ mesmo ocorrendo com a afirmação os treinamentos promoveram melhor socialização e integração com meus colegas. O resultado aponta para a prática de um dos tipos de treinamento, o de integração, voltado para a ambientação/adaptação do empregado (GONÇALVES, 2017; CHIAVENATO, 2004, 2010), muito embora ele não tenha sido citado pelos responsáveis como um dos frequentemente aplicados na Empresa $X$.

Para três colaboradores, maioria do grupo, os treinamentos revelaram que a Empresa $X$ não considera o funcionário em seus objetivos e expectativas pessoais (afirmação que recebeu três menções V e uma F). Quatro empregados anotaram $\mathrm{F}$ para as afirmações: os treinamentos que recebi contribuíram para a mudança no meu comportamento e os treinamentos que recebi contribuíram para eu repensar meus padrões de atuação. Ao mesmo tempo, os quatro assinalaram $\mathrm{V}$ para os treinamentos que eu recebi visaram apenas me preparar para produzir mais e melhor para a empresa. Esses resultados indicam que 
talvez a Empresa $X$ deva reconfigurar os treinamentos que realiza, desde 0 planejamento, mas, sinalizam, sobretudo, que talvez a empresa deva ouvir mais os seus colaboradores a respeito, o que contribuiria bastante para a sua análise sobre os treinamentos realizados.

Indagou-se ao colaborador se, na sua visão, os treinamentos têm sido positivos para os funcionários da Empresa $X$ como um todo e por quê? Três afirmaram que sim e um disse que não. O Colaborador $A$ afirmou que sim, "pois o treinamento agrega conhecimento aos funcionários da empresa, e consequentemente, um maior engajamento, causando melhoria de produtividade". Para o Colaborador B, "com os treinamentos as pessoas têm uma noção melhor sobre o que deve ser feito, como usar sistemas e como desempenhar da melhor forma as suas atividades, formando assim uma equipe mais alinhada com os objetivos da empresa e melhor preparada". O Colaborador $\mathrm{C}$ afirmou que sim "porque os treinamentos motivam os funcionários melhorando o seu desempenho. Eles otimizam processos e recursos e melhoram o clima organizacional". Já o Colaborador $D$, negando que os treinamentos sejam positivos para os empregados da Empresa $X$ como um todo, justificou da seguinte forma "porque tem áreas não recebem treinamento e áreas que recebem muito treinamento, então vendo o todo eu acredito que para o saldo positivo os treinamentos precisam atingir todas as áreas".

Apesar de a maioria do grupo ter afirmado que os treinamentos são positivos para os empregados da empresa em geral, e mesmo levando-se em conta as justificativas apresentadas (todas elas bastante coerentes e alinhadas com a literatura), o destaque, neste caso, vai para o Colaborador D quando relata a existência de maior número de treinamentos a pessoas de determinadas áreas da empresa enquanto outras, de outros setores, não recebem treinamento. Esse aspecto parece relevante, pois talvez indique que a Empresa $X$ prioriza treinamentos para uma parcela de colaboradores de certos setores, que, acredita-se, devam ser considerados mais sensíveis para o bom desenvolvimento do seu negócio principal.

A questão 8 pediu que o participante classificasse a eficiência dos treinamentos para ele, pessoalmente, no contexto de uma escala de 1 a 10, onde 1 é o menor nível e 10 o maior. O Colaborador A atribuiu classificação 4; o Colaborador B atribuiu 8; o Colaborador $C$ atribuiu classificação 2, em razão de nunca ter recebido treinamento e na comparação com áreas da empresa que receberam treinamentos. Já o Colaborador D, atribuiu classificação 5, comentando que, apesar da percepção de eficiência dos treinamentos, pensa 
que a Empresa $X$ poderia investir mais em treinamentos que aumentassem 0 desenvolvimento pessoal e técnico. A média de classificação dos quatro participantes foi, portanto, 4,75 , que não pode ser considerada positiva para a empresa. Deduz-se, assim, mais uma vez, que os treinamentos realizados pela Empresa $X$ talvez não venham atendendo às expectativas de seus funcionários.

$\mathrm{Na}$ questão 9, indagou-se ao participante se especificamente para ele os treinamentos da empresa têm sido satisfatórios e por quê. O Colaborador A afirmou que não, pois existe "pouco treinamento para o desenvolvimento profissional de curto e longo prazo". O Colaborador B afirmou que sim, porque ele pôde "desenvolver habilidades e conhecimentos que não tinha antes de entrar na empresa, já que o sistema que uso atualmente é diferente do antigo. A questão cultural também é importante, pois existem treinamentos obrigatórios para serem feitos assim que um novo funcionário entra na empresa".

Colaborador $\mathrm{C}$ afirmou que não "porque os treinamentos que recebi basicamente tratavam de leitura procedimentos da própria empresa. Não agregaram ao meu trabalho e/ou desenvolvimento pessoal". Já o Colaborador D afirmou que sim e que não. "Sim, no que tange aos procedimentos da própria empresa e não porque não agregaram ao meu desenvolvimento pessoal e técnico".

Portanto, para a maioria, os treinamentos da empresa não têm sido pessoalmente satisfatórios. Nesse sentido, apesar de um colaborador afirmar que os treinamentos o fizeram desenvolver conhecimentos e habilidades, outras justificativas se destacam, tais como: o fato de os treinamentos não promoverem desenvolvimento profissional para o curto e longo prazos e o fato de eles se limitarem a procedimentos da própria empresa, não agregando tecnicamente ao trabalho e ao desenvolvimento pessoal.

A última pergunta indagou se o participante tem críticas e/ou sugestões para a melhoria das atividades de treinamento realizadas pela Empresa $X$, e, em caso positivo, quais seriam. Dois dos colaboradores disseram que não têm sugestões ou críticas. Um terceiro afirmou não ter críticas nem sugestões, pois considera que o maior problema das empresas é a falta de treinamento. $O$ quarto colaborador sugeriu que a Empresa $X$ promova mais treinamentos para 0 pessoal dos escritórios, uma vez que, em sua maioria, eles são aplicados ao pessoal que trabalha embarcado. Deve-se levar em conta, assim, a observação de que é melhor ter treinamento do que não ter e a sugestão deste último participante. 


\section{Conclusões e recomendações para novos estudos}

Esta pesquisa tratou do tema treinamento corporativo, atualmente considerado parte integrante das estratégias das empresas, tendo em vista a relação entre competitividade e o melhor desempenho de seus quadros profissionais. Não por acaso, é significativo o aumento dos investimentos em treinamentos de pessoal. Apesar disso, vimos que há questionamentos quanto à forma como os treinamentos vêm sendo conduzidos pelas organizações. Autores identificam que várias empresas não consideram aspectos humanos nas suas práticas de treinamento, o que resultaria muitas vezes na frustração de expectativas profissionais e pessoais dos funcionários.

Tendo esta problematização, objetivou-se realizar um estudo que refletisse sobre treinamento corporativo, e, especificamente, que identificasse qual a percepção de um grupo de funcionários de uma empresa real sobre os treinamentos que recebe, confrontando essa percepção com a de outro grupo, formado por responsáveis pelos treinamentos ali realizados.

Basicamente, o trabalho foi dividido em dois momentos: revisão de literatura e pesquisa exploratória e descritiva. Na revisão de literatura, foram analisados a valorização do capital humano nas organizações, o conceito de gestão de pessoas e treinamento corporativo - em aspectos históricos e conceituais, tipos e técnicas. Foi possível verificar que, de acordo com a literatura, apesar das vantagens/benefícios, o treinamento também encontra barreiras/dificuldades, entre elas a questão problema que deu origem ao desenvolvimento do trabalho.

No segundo momento, realizou-se um estudo de caso da Empresa $X$, nome fictício de uma empresa real, de exploração e produção de petróleo e gás, que faz treinamentos com seus empregados. Deste estudo, que, por meio de entrevistas, comparou a percepção de dois grupos distintos sobre os treinamentos realizados pela empresa, algumas considerações a título conclusivo podem ser elaboradas, sendo as mais relevantes: 


\begin{tabular}{|c|c|}
\hline Conclusões & Recomendações \\
\hline $\begin{array}{l}\text { Treinamento corporativo, atualmente é } \\
\text { considerado parte integrante das estratégias das } \\
\text { empresas. }\end{array}$ & \multirow{2}{*}{$\begin{array}{l}\text { Por mais que a Empresa } X \text { tenha uma politica de } \\
\text { treinamentos corporativos, deve-se buscar melhorias } \\
\text { para integrar toda a equipe e gerar um nível maior } \\
\text { de capital intelectual. }\end{array}$} \\
\hline $\begin{array}{l}\text { É significativo o aumento dos investimentos em } \\
\text { treinamentos de pessoal. }\end{array}$ & \\
\hline $\begin{array}{l}\text { Responsáveis acreditam que a Empresa X valoriza o } \\
\text { capital humano, porem não realiza a avaliação pós } \\
\text { treinamento para validação do mesmo. } \\
\text { Média de eficiência dos treinamentos atribuída pelos } \\
\text { colaboradores foi de } 4,75\end{array}$ & $\begin{array}{l}\text { Seja feita uma observação sobre a metodologia de } \\
\text { levantamento de necessidades de treinamento adotada } \\
\text { pela empresa }\end{array}$ \\
\hline $\begin{array}{l}\text { Os treinamentos realizados nas instalações da empresa } \\
\text { são importantes para melhor desempenho. }\end{array}$ & \multirow{2}{*}{$\begin{array}{l}\text { Atualmente a empresa se utiliza em sua maioria de } \\
\text { treinamentos online por ser uma área de natureza } \\
\text { muito pratica, o interessante seriam treinamentos } \\
\text { presenciais com pessoas experientes no segmento. }\end{array}$} \\
\hline $\begin{array}{l}\text { A disponibilidade/falta de interesse dos colaboradores é } \\
\text { a principal barreira/dificuldade }\end{array}$ & \\
\hline
\end{tabular}

FONTE: Elaborado pelo autor.

\begin{tabular}{|l|l|}
\hline Conclusões & Recomendações \\
\hline $\begin{array}{l}\text { Os treinamentos revelam que a Empresa X não } \\
\text { considera objetivos e expectativas profissionais e } \\
\text { pessoais de seus empregados }\end{array}$ & $\begin{array}{l}\text { O levantamento das necessidades de treinamentos } \\
\text { devem contemplar os objetivos e expectativas dos } \\
\text { funcionários, para que o aproveitamento seja maior }\end{array}$ \\
\hline $\begin{array}{l}\text { Responsáveis pelos treinamentos não possuem ainda } \\
\text { uma concepção atual do conceito de treinamento } \\
\text { corporativo. }\end{array}$ & $\begin{array}{l}\text { Necessidade de um alinhamento, e conscientização } \\
\text { sobre a importância da cultura de treinamentos } \\
\text { corporativos. }\end{array}$ \\
\hline $\begin{array}{l}\text { Os colaboradores consideram que os treinamentos } \\
\text { recebidos voltam-se tão somente para prepará-los de } \\
\text { modo produzir mais e melhor para a empresa }\end{array}$ & $\begin{array}{l}\text { Os treinamentos devem ser melhor elaborados para } \\
\text { que os colaboradores se sintam parte atuante da } \\
\text { empresa, e sejam vistos como capital intelectual. }\end{array}$ \\
\hline
\end{tabular}

FONTE: Elaborado pelo autor.

Atualmente na empresa $X$ não existe uma cultura sobre treinamento corporativo, visto que, os funcionários não conseguem definir de forma clara o que é treinamento para eles, devido ao fato de um funcionário afirmar que fez 10 treinamentos em um ano, e outro em 3 anos de empresa não ter feito nenhum treinamento.

1) A empresa tem como principal recomendação após essa pesquisa, que uma observação seja feita sobre como os treinamentos são construídos, desenvolvidos, aplicados, portanto uma nova metodologia no levantamento de necessidades de treinamentos deve ser adotada pela empresa.

2) O grupo de responsáveis pelos treinamentos não possui ainda uma concepção atual do conceito de treinamento corporativo, apesar de não considerar treinamento uma espécie de adestramento de pessoas; 
3) O grupo de responsáveis considera positivos os resultados dos treinamentos para a Empresa X. A maioria dos participantes do grupo de colaboradores, por outro lado, considera positivos os treinamentos para os empregados como um todo e satisfatórios do ponto de vista pessoal. No entanto, a média de eficiência dos treinamentos atribuída pelos membros do grupo de colaboradores foi de 4,75;

4) Para a maioria do grupo de colaboradores, os treinamentos realizados nas instalações da empresa são importantes para o seu melhor desempenho;

5) A falta de interesse é considerada a maior barreira ou dificuldade para os responsáveis pelo treinamento, portanto o interessante é que a empresa adote treinamentos presenciais com pessoas experientes no mercado.

6) A maioria dos componentes do grupo de responsáveis acredita que a Empresa $X$ valoriza o capital humano e seu capital intelectual, que possui cultura organizacional voltada para o desenvolvimento das pessoas, que adota o conceito de gestão de pessoas, que considera 0 $\mathrm{RH}$ um setor estratégico e que aplica as melhores práticas em termos de treinamento. De outra parte, a maioria dos componentes do grupo de colaboradores não recebe feedback da empresa após ter sido treinada;

7) De modo geral, para o grupo de responsáveis, a disponibilidade/falta de interesse dos colaboradores é a principal barreira/dificuldade na realização de treinamentos. Contudo, a maioria dos participantes do grupo de colaboradores diz sentir-se envolvida com os treinamentos da empresa, embora todos eles reconheçam que esses treinamentos não são orientados também à satisfação de suas expectativas;

8) Para a maioria do grupo de colaboradores, os treinamentos revelam que a Empresa $X$ não considera objetivos e expectativas profissionais e pessoais de seus empregados;

9) A maioria dos colaboradores não considera que os treinamentos da Empresa $X$ contribuem para a mudança no seu comportamento e que eles não contribuem para a promoção de mudanças nos seus padrões de atuação. Todos consideram que os treinamentos recebidos voltamse tão somente para prepará-los de modo produzir mais e melhor para a empresa; 
10) A maioria de ambos os grupos não fez críticas ou sugestões para o aperfeiçoamento do processo de treinamento na Empresa $X$. 


\section{Referências Bibliográficas}

AMARAL, C.S. Avaliação do Sistema Capacita: a eficiência no levantamento das necessidades de treinamento. Brasília, 2014. 105 p. Trabalho de Conclusão de Curso - Programa de Pós-Graduação em Administração Legislativa: Instituto Legislativo Brasileiro (ILB).

ANTUNES, E.D.D.; PICCININI, V.C.; SILVA, L.V. Os Novos e Múltiplos Papéis dos Gestores de $\mathrm{RH}$ : o caso de uma empresa calçadista do $\mathrm{RS}$ analisado à luz do modelo de Ulrich. READ, Revista Eletrônica de Administração, v. 6, n. 4, p. 01-12, Porto Alegre, UFRGS, 2000.

BOOG, G.G. Manual de Treinamento e Desenvolvimento: um guia de operações. Manual Oficial da ABTD. São Paulo: Makron Books, 2001.

CARVALHO, L.C.F. T\&D Estratégicos. In: BOOG, G.G. (coord.). Manual de Treinamento e Desenvolvimento. São Paulo: Makron Books, 1999.

CHIAVEnATO, I. Gestão de Pessoas. Rio de Janeiro: Elsevier, 2004.

CHIAVENATO, I. Gestão de Pessoas: o novo papel dos recursos humanos nas organizações. Rio de Janeiro: Campus Elsevier, 2010.

CHIAVENATO, I. Recursos Humanos: o capital intelectual nas organizações. Rio de Janeiro: Campus Elsevier, 2008.

COSTA, A.C.B.; SANTANA, L. A influência dos treinamentos comportamentais corporativos na vida pessoal: a percepção do funcionário operacional. Cairu em Revista, n. 2, p. 174-190, Salvador, janeiro de 2013.

DRUCKER, P. Sociedade Pós-capitalista. São Paulo: Pioneira Thomson Learning, 2001.

DUTRA, J.S. Gestão de Pessoas: modelo, processos, tendências e perspectivas. São Paulo: Atlas, 2009.

FITZ-ENZ, J. Retorno do Investimento em Capital Humano: medindo o valor do desempenho dos funcionários. São Paulo: Makron Books, 2001.

FRESCHI, C.P. et al. Treinamento e desenvolvimento profissional: um programa de qualidade no atendimento ao público para o campus da Unesp de Bauru. Anais do XIII SIMPEP. Bauru, 06 a 08 de novembro de 2006.

GIL, A.C. Como Elaborar Projetos de Pesquisa. São Paulo: Atlas, 2009.

GIL, A.C. Métodos e Técnicas de Pesquisa Social. São Paulo: Atlas, 2008.

GONÇALVES, P.M. O Psicólogo nas Organizações de Treinamento. Psicologia.com.pt. Disponível em: < 
http://www.psicologia.pt/artigos/textos/A0263.pdf > Acesso em: 20 de julho de 2017.

MAIR, J. Chega de oba-oba! Por que desempenho e disciplina rendem mais que inteligência emocional, espírito de equipe e soft skills. São Paulo: Martins Fontes, 2005.

MILKOVICH, G.T.; BOUDREAU, J. Administração de Recursos Humanos. São Paulo: Atlas, 2006.

PEREIRA, F.C.M. O processo de conversão do conhecimento em uma escola de atendimento especializado. Revista Encontros Bibli, v. 10, p. 39-52, UFSC, 2007.

PILLA, B.S. A Dimensão Humana nas Estratégias de Treinamento e Desenvolvimento do Sistema de Ensino a Distância de uma Empresa de Telecomunicações. Porto Alegre, 2002. 154 p. Dissertação (Mestrado em Administração) - Programa de Pós-Graduação em Administração: Universidade Federal do Rio Grande do Sul.

REVISTA T\&D, Inteligência Corporativa. O panorama do treinamento no Brasil: fatos, indicadores, tendências e análises. São Paulo: T\&D Inteligência Corporativa, 2016.

RICHIE, G.A.; MONTE ALTO, R. As organizações que aprendem, segundo Peter Senge: "A Quinta Disciplina". Cadernos Discentes COPPEAD, n. 9, p. 36-55, Rio de Janeiro, 2001.

RISE, Desenvolvimento Humano. 50 Indicadores para Você Investir em Treinamento e Desenvolvimento. São Paulo, 2015.

SANTOS, J.L. et al. Capital Intelectual: o recurso econômico do novo milênio. Business Review, v. 4, p. 55-77, Porto Alegre, UNIFIN, setembro/dezembro de 2007.

STEWART, T.A. Capital Intelectual: a nova vantagem competitiva das empresas. Rio de Janeiro: Campus, 2002.

SVEIBY, K.E. A Nova Riqueza das Organizações: gerenciando e avaliando patrimônios de conhecimento. Rio de Janeiro: Campus, 1998.

VERGARA, S.C. Projetos e Relatórios de Pesquisa em Administração. São Paulo: Atlas, 2010.

YIN, Robert K. Estudo de Caso: planejamento e métodos. Porto Alegre: Bookman, 2010. 


\section{Anexo 1}

Prezado participante, esta entrevista é parte de um trabalho acadêmico de conclusão de curso de graduação em Administração cujo tema é treinamento corporativo. Seu objetivo principal é conhecer a sua visão sobre os treinamentos realizados pela Empresa X. Agradeço a colaboração e reitero o compromisso de manter sigilo quanto às informações obtidas.

Dados Gerais:

Gênero: ( ) Masculino （ ) Feminino

Idade:

Cargo:

Tempo na empresa:

Tempo como responsável pelo treinamento:

1) Para você, o que é treinamento corporativo?

( ) É uma espécie de adestramento de recursos humanos para que eles sejam produtivos no desempenho de tarefas específicas do cargo que ocupam

( ) Processo que faz parte do desenvolvimento e aprendizagem contínua das pessoas, tornando-se uma via para que as empresas alcancem suas metas e seus objetivos

( ) Uma forma de aprimorar as habilidades dos recursos humanos para que a empresa ganhe em produtividade

2) Aponte vantagens/benefícios dos treinamentos (não precisa completar o número sugerido)

1)

2)

3)

4)

3) Aponte barreiras/dificuldades dos treinamentos (não precisa completar o número sugerido) 
1)

2)

3)

4)

4) Sobre a Empresa $X$, assinale V (verdadeiro) ou $F$ (falso):

A Empresa X valoriza o capital humano e seu capital intelectual, pois requer aprendizado constante de seus colaboradores

A Empresa X não tem cultura organizacional voltada para a expansão do conhecimento de seus colaboradores

A Empresa $X$ ainda possui uma visão mecanicista do setor de $\mathrm{RH}$

$\mathrm{O}$ setor de $\mathrm{RH}$ da Empresa $\mathrm{X}$ trabalha com o conceito de gestão de pessoas em todos os seus aspectos

O setor de $\mathrm{RH}$ não é estratégico na empresa

5) Aponte algumas razões para que a Empresa $X$ realize treinamentos (não precisa completar o número sugerido)

1)

2)

3)

4)

6) Que tipos de treinamento são mais frequentemente empregados na Empresa $X$ ?

( ) Treinamento de integração de novos colaboradores

( ) Treinamento técnico-operacional (voltado para a capacitação técnica do colaborador para o desempenho de suas funções no cargo e assimilação operacional para o desempenho de tarefas específicas)

( ) Treinamento gerencial (aplicado a colaboradores que exercem cargos de chefia, gerentes ou executivos)

( ) Treinamento comportamental (aplicado para melhorar as relações entre as pessoas no ambiente de trabalho)

7) Quais as técnicas mais frequentemente utilizadas nos treinamentos da empresa? Assinale com um $\mathrm{X}$.

\begin{tabular}{|l|l|}
\hline Aulas expositivas & \\
\hline Leituras & \\
\hline Estágios & \\
\hline Palestras & \\
\hline
\end{tabular}




\begin{tabular}{|l|l|}
\hline Workshops & \\
\hline Conferências e Seminários & \\
\hline Cursos presenciais & \\
\hline Jogos cooperativos & \\
\hline Dinâmicas e discussões em grupo & \\
\hline Dramatizações & \\
\hline Estudos de caso & \\
\hline Instrução on-line & \\
\hline Videoconferências & \\
\hline Treinamento a distância (e-learning) & \\
\hline Laboratório virtual, livro eletrônico, e-mail, chats, sites \\
\hline
\end{tabular}

8) Qual a periodicidade dos treinamentos realizados pela Empresa $X$ e quantos empregados (aproximadamente) eles abrangem?

Perioricidade:

Número de empregados:

9) Os resultados dos treinamentos têm sido positivos para a Empresa $X$ ?

( ) Sim

Por quê?

( ) Não

Por quê?

10) Você tem sugestões e/ou críticas para a melhoria das atividades de treinamento e desenvolvimento de pessoal realizadas pela Empresa $X$ ? Em caso positivo, quais? 


\section{Anexo 2}

Prezado participante, esta entrevista é parte de um trabalho acadêmico de conclusão de curso de graduação em Administração cujo tema é treinamento corporativo. Seu objetivo principal é conhecer a sua visão sobre os treinamentos realizados pela Empresa X. Agradeço a colaboração e reitero o compromisso de manter sigilo quanto às informações obtidas.

Dados Gerais:

Gênero: ( ) Masculino （ ) Feminino

Idade:

Cargo:

Tempo na empresa:

Número de treinamentos da Empresa $\mathrm{X}$ recebidos até o momento:

1) Você acha importante a aplicação de treinamentos dentro das instalações da empresa?

( ) $\mathrm{Sim}$

Por quê?

( ) Não

Por quê?

2) Sobre a Empresa $X$, assinale V (verdadeiro) ou $F$ (falso). 


\begin{tabular}{|l|l|}
\hline A Empresa X estimula o desenvolvimento profissional de seus empregados & \\
\hline $\begin{array}{l}\text { A Empresa } X \text { não tem cultura organizacional voltada para a expansão do } \\
\text { conhecimento de seus colaboradores }\end{array}$ & \\
\hline $\begin{array}{l}\text { A Empresa X desenvolve treinamentos para aumentar a produtividade da } \\
\text { organização }\end{array}$ & \\
\hline Os empregados da Empresa X são vistos como recursos & \\
\hline $\begin{array}{l}\text { Em geral, a Empresa X reconhece o potencial humano de seu quadro de } \\
\text { colaboradores }\end{array}$ & \\
\hline Os empregados da Empresa X são vistos como parceiros & \\
\hline
\end{tabular}

3) Assinale com um $X$ as técnicas de treinamento que a Empresa $X$ empregou nos treinamentos que você recebeu.

\begin{tabular}{|l|l|}
\hline Aulas expositivas & \\
\hline Leituras & \\
\hline Estágios & \\
\hline Palestras & \\
\hline Workshops & \\
\hline Conferências e Seminários & \\
\hline Cursos presenciais & \\
\hline Jogos cooperativos & \\
\hline Dinâmicas e discussões em grupo & \\
\hline Dramatizações & \\
\hline Estudos de caso & \\
\hline Instrução on-line & \\
\hline Videoconferências & \\
\hline Treinamento a distância (e-learning) & \\
\hline Laboratório virtual, livro eletrônico, e-mail, chats, sites & \\
\hline
\end{tabular}

4) Você se sente envolvido com os treinamentos que recebe na Empresa $X$ ?

( ) Sim

O quadro abaixo apresenta dez razões para que você se sinta envolvido. Dentre elas, assinale as cinco mais importantes.

\begin{tabular}{|l|l|}
\hline Porque tenho grande interesse em ser treinado pela empresa & \\
\hline Porque os treinamentos da empresa são bem planejados e executados & \\
\hline Porque me sinto motivado por ver que a empresa valoriza as pessoas & \\
\hline $\begin{array}{l}\text { Porque os treinamentos me proporcionam benefícios objetivos dentro da } \\
\text { empresa (por exemplo, ganhando pontos na avaliação de desempenho) }\end{array}$ & \\
\hline $\begin{array}{l}\text { Porque os treinamentos que a Empresa X realiza são também orientados para } \\
\text { satisfazer as minhas necessidades e expectativas pessoais }\end{array}$ & \\
\hline $\begin{array}{l}\text { Porque os treinamentos da empresa proporcionam o nível de aproveitamento } \\
\text { que desejo }\end{array}$ & \\
\hline Porque os treinamentos me ajudam a solucionar problemas do meu setor & \\
\hline Porque é uma oportunidade de me desenvolver & \\
\hline Porque as técnicas utilizadas são modernas & \\
\hline $\begin{array}{l}\text { Porque os treinamentos realizados pela empresa me preparam para atuar em } \\
\text { outras empresas, aumentando minhas chances profissionais }\end{array}$ & \\
\hline
\end{tabular}




\section{( ) Não}

O quadro abaixo apresenta dez razões para que você não se sinta envolvido.

Dentre elas, assinale as cinco mais importantes.

\begin{tabular}{|l|l|}
\hline $\begin{array}{l}\text { Porque os treinamentos não acrescentam para a prática do dia a dia na } \\
\text { empresa }\end{array}$ & \\
\hline $\begin{array}{l}\text { Porque, na minha visão, os treinamentos realizados não são bem planejados e } \\
\text { executados, não tendo resultados eficazes }\end{array}$ & \\
\hline Porque não somos convocados a avaliar o treinamento recebido & \\
\hline $\begin{array}{l}\text { Porque não me sinto motivado, uma vez que a Empresa X não valoriza os } \\
\text { colaboradores }\end{array}$ & \\
\hline Porque, na verdade, a empresa treina pouco seus funcionários & \\
\hline Porque as técnicas utilizadas são muito antiquadas & \\
\hline $\begin{array}{l}\text { Porque os treinamentos não me oferecem benefícios objetivos, como prêmios, } \\
\text { por exemplo }\end{array}$ & \\
\hline $\begin{array}{l}\text { Porque os treinamentos não me proporcionam o nível de aproveitamento que } \\
\text { desejo }\end{array}$ & \\
\hline $\begin{array}{l}\text { Porque os treinamentos que a Empresa X realiza não são orientados para } \\
\text { satisfazer as minhas necessidades e expectativas pessoais }\end{array}$ & $\begin{array}{l}\text { Porque os treinamentos da Empresa X não aumentam minhas chances de } \\
\text { atuação profissional }\end{array}$ \\
\hline
\end{tabular}

5) Você recebe um feedback da empresa sobre o seu desempenho após receber um treinamento?

( ) Sim

( ) Não

6) Dentre as alternativas abaixo, assinale $\mathrm{V}$ (verdadeiro) ou $\mathrm{F}$ (falso).

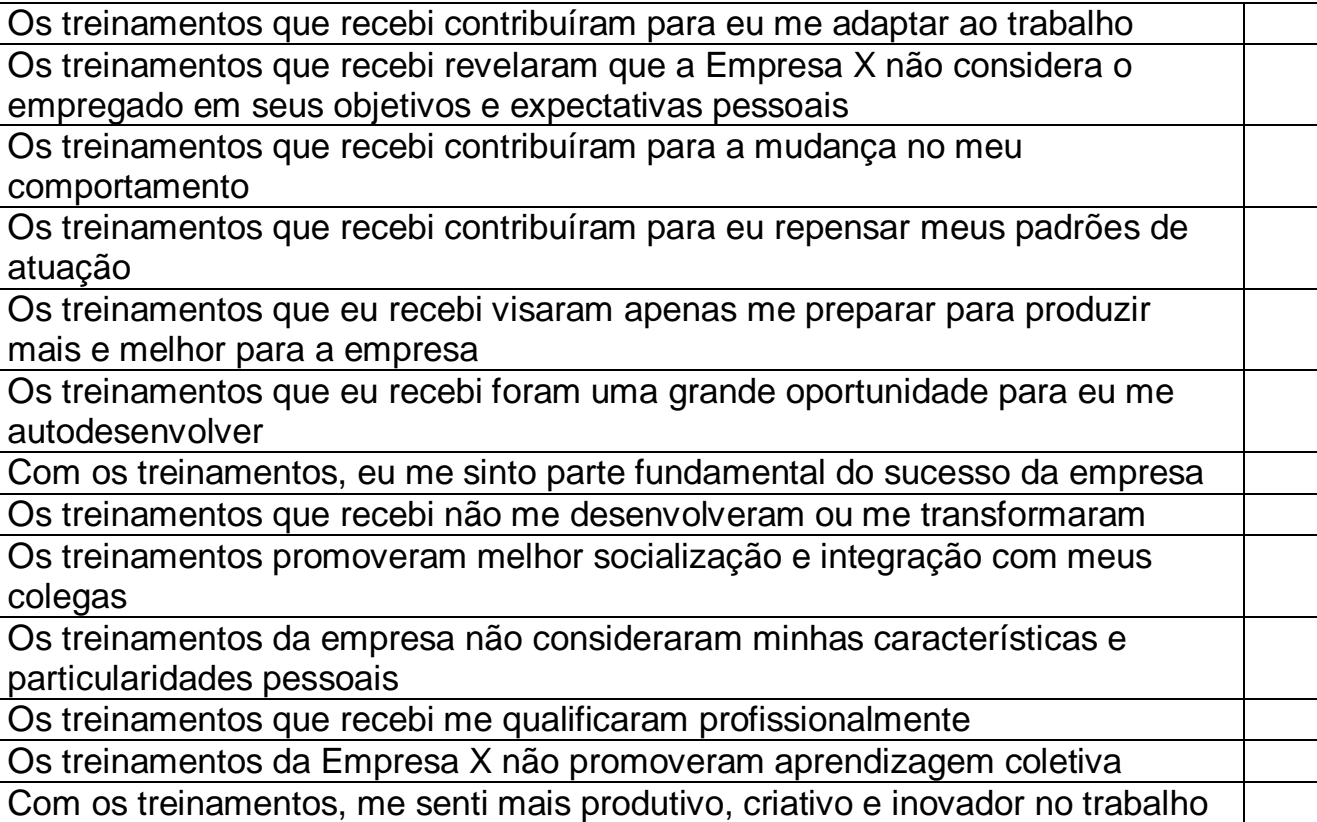


7) Na sua visão, os treinamentos têm sido positivos para os empregados da Empresa $\mathrm{X}$ como um todo?

( ) Sim

Por quê?

( ) Não

Por quê?

8) Numa escala de 1 a 10 (onde 1 é o menor nível e 10 o maior) classifique a eficiência dos treinamentos da Empresa $X$ para você pessoalmente.

9) Especificamente para você os treinamentos da Empresa $X$ têm sido satisfatórios?

( ) Sim

Por quê?

( ) Não

Por quê? 
10) Você tem sugestões e/ou críticas para a melhoria das atividades de treinamento e desenvolvimento de pessoal realizadas pela Empresa $X$ ? Em caso positivo, quais? 